(6)

OPEN ACCESS

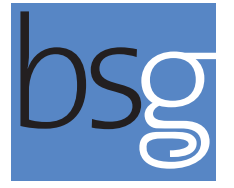

BRITISH SOCIETY OF GASTROENTEROLOGY

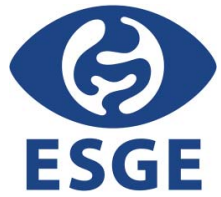

For numbered affiliations see end of article.

\section{Correspondence to}

Dr Andrew Veitch, Department of Gastroenterology, New

Cross Hospital, Wolverhampton WV10 OQP, UK;

andrew.veitch@nhs.net

This article is published simultaneously in the journal Endoscopy. Copyright 2016 @ Georg Thieme Verlag KG

Received 16 November 2015 Revised 30 December 2015 Accepted 4 January 2016

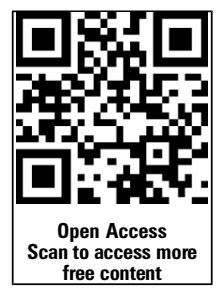

\title{
Endoscopy in patients on antiplatelet or anticoagulant therapy, including direct oral anticoagulants: British Society of Gastroenterology (BSG) and European Society of Gastrointestinal Endoscopy (ESGE) guidelines
}

\author{
Andrew M Veitch, ${ }^{1}$ Geoffroy Vanbiervliet, ${ }^{2}$ Anthony H Gershlick, ${ }^{3}$ Christian Boustiere, ${ }^{4}$ \\ Trevor P Baglin, ${ }^{5}$ Lesley-Ann Smith, ${ }^{6}$ Franco Radaelli, ${ }^{7}$ Evelyn Knight, ${ }^{8}$ \\ Ian M Gralnek, ${ }^{9,10}$ Cesare Hassan, ${ }^{11}$ Jean-Marc Dumonceau ${ }^{12}$
}

\section{ABSTRACT}

The risk of endoscopy in patients on antithrombotics depends on the risks of procedural haemorrhage versus thrombosis due to discontinuation of therapy.

P2Y12 receptor antagonists (clopidogrel, prasugrel, ticagrelor) For low-risk endoscopic procedures we recommend continuing P2Y12 receptor antagonists as single or dual antiplatelet therapy (low quality evidence, strong recommendation); For high-risk endoscopic procedures in patients at low thrombotic risk, we recommend discontinuing P2Y12 receptor antagonists five days before the procedure (moderate quality evidence, strong recommendation). In patients on dual antiplatelet therapy, we suggest continuing aspirin (low quality evidence, weak recommendation). For highrisk endoscopic procedures in patients at high thrombotic risk, we recommend continuing aspirin and liaising with a cardiologist about the risk/benefit of discontinuation of P2Y12 receptor antagonists (high quality evidence, strong recommendation).

Warfarin The advice for warfarin is fundamentally unchanged from British Society of Gastroenterology (BSG) 2008 guidance.

Direct Oral Anticoagulants (DOAC) For low-risk endoscopic procedures we suggest omitting the morning dose of DOAC on the day of the procedure (very low quality evidence, weak recommendation); For high-risk endoscopic procedures, we recommend that the last dose of DOAC be taken $\geq 48 \mathrm{~h}$ before the procedure (very low quality evidence, strong recommendation). For patients on dabigatran with $\mathrm{CrCl}$ (or estimated glomerular filtration rate, eGFR) of $30-50 \mathrm{~mL} / \mathrm{min}$ we recommend that the last dose of DOAC be taken $72 \mathrm{~h}$ before the procedure (very low quality evidence, strong recommendation). In any patient with rapidly deteriorating renal function a haematologist should be consulted (low quality evidence, strong recommendation).

\subsection{SUMMARY OF RECOMMENDATIONS}

These guidelines refer to patients undergoing elective endoscopic gastrointestinal procedures. Management of antiplatelet therapy and direct oral anticoagulants (DOACs) in acute gastrointestinal haemorrhage is discussed in detail in European Society of Gastrointestinal Endoscopy (ESGE) guidelines on the management of acute nonvariceal upper gastrointestinal bleeding. ${ }^{1}$

Recommendations for the management of patients on antiplatelet therapy or anticoagulants undergoing elective endoscopic procedures are outlined in the algorithms in figures 1 and 2. Risk stratification for endoscopic procedures and antiplatelet agents (APAs) are detailed in tables 1 and 2. There is no high-risk category of thrombosis for DOACs as they are not indicated for prosthetic metal heart valves. Warfarin risk stratification is detailed in table 3. Our recommendations are based on best estimates of risk:benefit analysis for thrombosis versus haemorrhage. When discontinuing antithrombotic therapy, patient preference should be considered as well as clinical opinion: the risk of a potentially catastrophic thrombotic event such as a stroke may not be acceptable to a patient even if that risk is very low.

For all endoscopic procedures we recommend continuing aspirin (moderate evidence, strong recommendation), with the exception of endoscopic submucosal dissection (ESD), large colonic endoscopic mucosal resection (EMR) (>2 cm), upper gastrointestinal EMR and ampullectomy. In the latter cases, aspirin discontinuation should be considered on an individual patient basis depending on the risks of thrombosis versus haemorrhage (low quality evidence, weak recommendation).

\subsection{Low-risk procedures}

For low-risk endoscopic procedures we recommend continuing P2Y12 receptor antagonists (eg, clopidogrel), as single or dual antiplatelet therapy (low quality evidence, strong recommendation).

For low-risk endoscopic procedures we suggest that warfarin therapy should be continued (low quality evidence, weak recommendation). It should be ensured that the International normalised ratio (INR) does not exceed the therapeutic range in the week prior to the procedure (low quality evidence, strong recommendation).

For low-risk endoscopic procedures we suggest omitting the morning dose of DOACs on the day of the procedure (very low quality evidence, weak recommendation) 

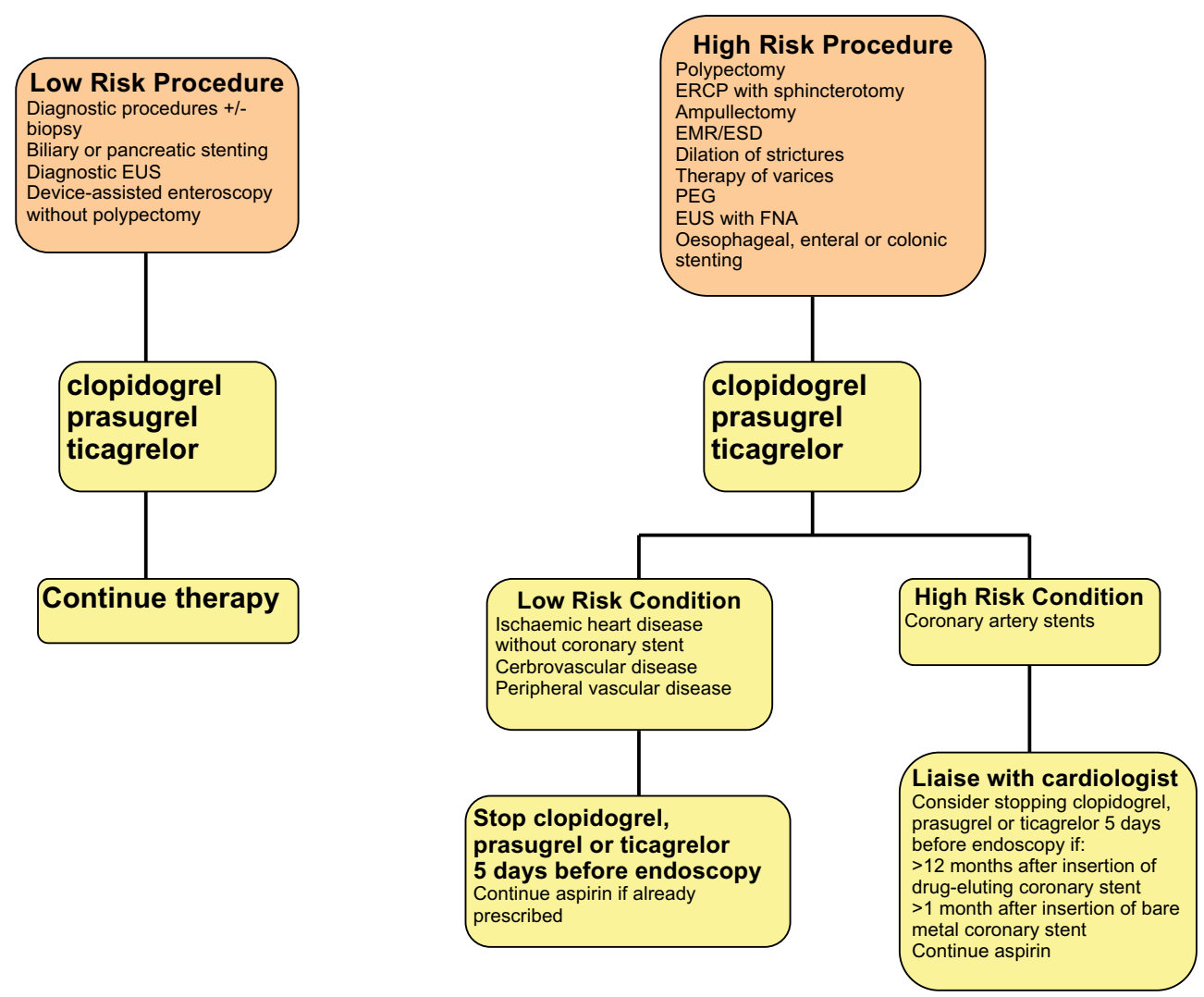

Figure 1 Guidelines for the management of patients on P2Y12 receptor antagonist antiplatelet agents undergoing endoscopic procedures.

\subsection{High-risk procedures}

For high-risk endoscopic procedures in patients at low thrombotic risk, we recommend discontinuing $P 2 Y 12$ receptor antagonists (eg, clopidogrel) five days before the procedure (moderate quality evidence, strong recommendation). In patients on dual antiplatelet therapy, we suggest continuing aspirin (low quality evidence, weak recommendation).

For high-risk endoscopic procedures in patients at low thrombotic risk, we recommend discontinuing warfarin 5 days before the procedure (bigh quality evidence, strong recommendation).
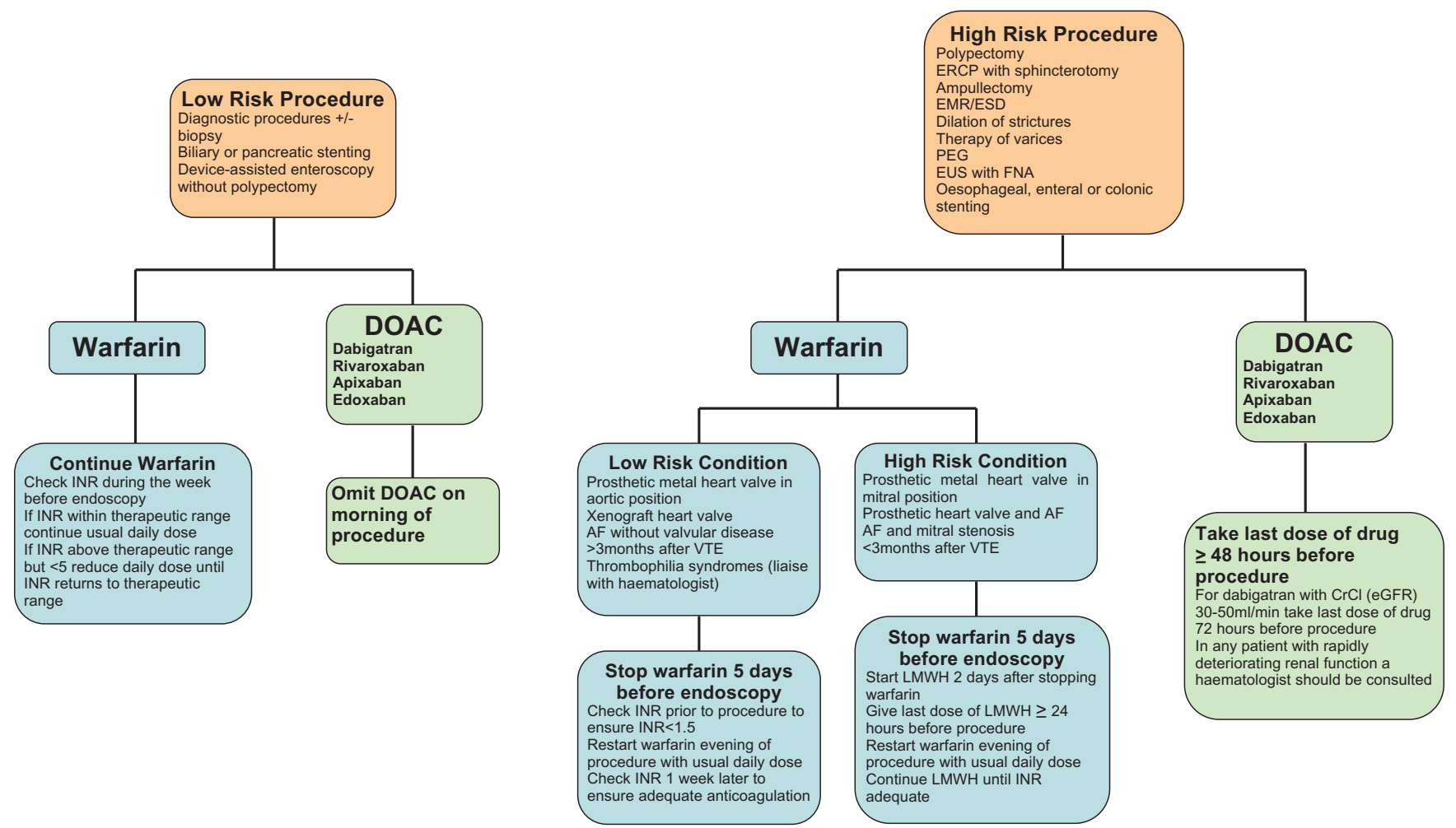

Figure 2 Guidelines for the management of patients on warfarin or direct oral anticoagulants (DOAC) undergoing endoscopic procedures. 
Table 1 Risk stratification of endoscopic procedures based on the risk of haemorrhage

\begin{tabular}{ll}
\hline High risk & Low risk \\
\hline $\begin{array}{l}\text { Endoscopic polypectomy } \\
\text { ERCP with sphincterotomy }\end{array}$ & $\begin{array}{l}\text { Diagnostic procedures } \pm \text { biopsy } \\
\text { Biliary or pancreatic stenting } \\
\text { Device-assisted enteroscopy } \\
\text { wilatation }\end{array}$ \\
$\begin{array}{l}\text { Ampullectomy } \\
\text { Endoscopic mucosal resection or endoscopic }\end{array}$ \\
submucosal dissection \\
$\begin{array}{l}\text { Endoscopic dilatation of strictures in the } \\
\text { upper or lower GI tract }\end{array}$ \\
$\begin{array}{l}\text { Endoscopic therapy of varices } \\
\text { Percutaneous endoscopic gastrostomy }\end{array}$ \\
Endoscopic ultrasound with fine needle \\
aspiration \\
Oesophageal, enteral or colonic stenting \\
\hline ERCP, Endoscopic Retrograde Cholangiopancreatography.
\end{tabular}

Check INR prior to the procedure to ensure $<1.5$ (low quality evidence, strong recommendation).

For high-risk endoscopic procedures in patients at bigh thrombotic risk, we recommend continuing aspirin and liaising with a cardiologist about the risk/benefit of discontinuing P2Y12 receptor antagonists (eg, clopidogrel) (bigh quality evidence, strong recommendation).

For high-risk endoscopic procedures in patients at high thrombotic risk, we recommend that warfarin should be temporarily discontinued and substituted with low molecular weight heparin (LMWH) (low quality evidence, strong recommendation).

For all patients on warfarin we recommend advising that there is an increased risk of post-procedure bleeding compared to non-anticoagulated patients (low quality evidence, strong recommendation).

For high-risk endoscopic procedures in patients on DOACs, we recommend that the last dose of DOACs be taken at least $48 \mathrm{~b}$ before the procedure (very low quality evidence, strong recommendation). For patients on dabigatran with a $\mathrm{CrCl}$ (or estimated glomerular filtration rate (eGFR)) of 30-50 $\mathrm{mL} / \mathrm{min}$ we recommend that the last dose be taken $72 \mathrm{~b}$ prior to the procedure (very low quality evidence, strong recommendation). In any patient with rapidly deteriorating renal function a haematologist should be consulted (low quality evidence, strong recommendation).

\subsection{Post endoscopic procedure}

If antiplatelet or anticoagulant therapy is discontinued, then we recommend this should be resumed up to $48 \mathrm{~h}$ after the procedure depending on the perceived bleeding and thrombotic risks (moderate quality evidence, strong recommendation).

Table 2 Risk stratification for discontinuation of clopidogrel, prasugrel or ticagrelor based on the risk of thrombosis

\begin{tabular}{ll}
\hline High risk & Low risk \\
\hline $\begin{array}{ll}\text { Drug eluting coronary artery stents within } \\
12 \text { months of placement }\end{array}$ & $\begin{array}{l}\text { Ischaemic heart disease without } \\
\text { coronary stents } \\
\text { Bare metal coronary artery stents within } \\
1 \text { month of placement }\end{array}$ \\
& Peripheral vascular disease \\
\hline
\end{tabular}

Table 3 Risk stratification for discontinuation of warfarin therapy with respect to the requirement for heparin bridging

\begin{tabular}{ll}
\hline High risk & Low risk \\
\hline $\begin{array}{l}\text { Prosthetic metal heart valve in } \\
\text { mitral position }\end{array}$ & $\begin{array}{l}\text { Prosthetic metal heart valve in aortic } \\
\text { position } \\
\text { Xenograft heart valve }\end{array}$ \\
$\begin{array}{l}\text { Prosthetic heart valve and atrial } \\
\text { fibrillation }\end{array}$ & Atrial fibrillation without valvular disease \\
$\begin{array}{l}\text { Atrial fibrillation and mitral } \\
\text { stenosis* }\end{array}$ & $>3$ months after venous \\
$<3$ months after venous & thromboembolism \\
thromboembolism & $\begin{array}{l}\text { Thrombophilia syndromes (discuss with } \\
\text { haematologist) }\end{array}$ \\
& $\begin{array}{l}\text { hom } \\
\text { * Uncertainty exists regarding the thrombotic risk of temporarily discontinuing } \\
\text { warfarin in patients with atrial fibrillation and mitral stenosis following the BRIDGE } \\
\text { trial, }{ }^{17} \text { but there is insufficient evidence at present to alter the risk category. }\end{array}$
\end{tabular}

\subsection{ORIGIN AND PURPOSE OF THESE GUIDELINES}

Anticoagulants and APAs are widely prescribed for a number of cardiovascular and thromboembolic conditions with established benefit to patients. These drugs confer an increased risk of haemorrhage when undertaking therapeutic endoscopic procedures, but also pose risks of thromboembolic sequelae if discontinued. The British Society of Gastroenterology (BSG) published guidelines on the management of anticoagulants and APAs in patients undergoing endoscopy in $2008^{2}$ and the ESGE published guidelines on endoscopy and APAs in 2011. ${ }^{3}$ Both guidelines are due for revision, and the BSG and ESGE have cooperated to produce a joint guideline. Since the publication of the previous guidelines there has been an expansion in the use of the newer antiplatelet drugs, and new oral anticoagulant drugs have been introduced. The latter have been widely prescribed and pose particular problems for endoscopists with regard to haemorrhage; their effects are difficult to reverse in an emergency situation, and moreover some of these drugs are associated with a higher incidence of spontaneous gastrointestinal haemorrhage compared to warfarin.

\subsection{PREPARATION OF THE GUIDELINES}

These guidelines were drafted by a working party comprising members of the BSG and ESGE, a haematologist, interventional cardiologist, and a patient representative from the charity AntiCoagulation Europe. Guidelines were prepared according to AGREE II principles ${ }^{4}$ and comply with the requirements of the National Institute for Health and Care Excellence (NICE). Clinical questions were formulated using the PICO (Patients, Interventions, Controls, Outcomes) system. Search strategies were delegated to authors with responsibilities for specific sections. Literature searches were conducted using PubMed and OVID Medline, Embase and Cochrane Library. Additional searches were conducted using Google. Literature searches were re-run in February 2015, and any additional relevant studies considered up to August 2015. Quality of evidence and strength of recommendations were determined by the authors and consensus achieved according to the GRADE system. ${ }^{5}$ After agreement on a final version, the manuscript was subjected to internal peer review and revision by the BSG and the ESGE and sent to all individual ESGE members and member societies prior to publication. Conflict of interest statements were submitted by all authors. This guideline was produced in 2015 and will be considered for review in 2019, or sooner if new evidence becomes available. This guideline has been co-published with permission in both Gut and Endoscopy. 


\subsection{WARFARIN}

For low-risk endoscopic procedures we suggest that warfarin therapy should be continued (low quality evidence, moderate recommendation). It should be ensured that the INR does not exceed the therapeutic range in the week prior to the procedure (low quality evidence, strong recommendation).

- Tell the patient to continue warfarin and check the INR during the week before the endoscopy;

- If the INR result is within the therapeutic range then continue with the usual daily dose;

- If the INR result is above the therapeutic range, but less than 5 , then reduce the daily warfarin dose until the INR returns to within the therapeutic range;

- If the INR is greater than 5 then defer the endoscopy and contact the anticoagulation clinic, or a medical practitioner, for advice.

For high-risk endoscopic procedures in patients at low thrombotic risk, we recommend discontinuing warfarin 5 days before the procedure (high quality evidence, strong recommendation). Check INR prior to the procedure to ensure $<1.5$ (low quality evidence, strong recommendation)

- Stop warfarin 5 days before the endoscopy;

- Check the INR prior to the procedure to ensure its value is $<1.5$;

- On the day of the procedure restart warfarin with the usual daily dose that night;

- Check INR one week later to ensure adequate anticoagulation.

For high-risk endoscopic procedures in patients at high thrombotic risk, we recommend that warfarin should be temporarily discontinued and substituted with LMWH (moderate quality evidence, strong recommendation).

- Warfarin should be stopped 5 days before the procedure;

- Two days after stopping warfarin commence daily therapeutic dose of LMWH;

- Administer the last dose of LMWH at least $24 \mathrm{~h}$ prior to the procedure;

- Check the INR prior to the procedure to ensure its value is $<1.5$;

- Warfarin can be resumed on the day of the procedure with the usual dose that night;

- Restart the daily therapeutic dose of LMWH on the day after the procedure;

- Continue LMWH until a satisfactory INR is achieved.

For all patients on warfarin we recommend advising that there is an increased risk of post-procedure bleeding compared to non-anticoagulated patients (low quality evidence, strong recommendation).

Updated literature searches were conducted on the use of warfarin and heparin in patients undergoing endoscopy. Two studies of colonic polypectomy on warfarin for small polyps have been retrieved. A retrospective study of 223 polypectomies $(<1 \mathrm{~cm})$ in 123 patients on continued warfarin therapy found a rate of haemorrhage requiring transfusion of $0.8 \%$. This was despite routine prophylactic clipping of polypectomies. ${ }^{6}$ In a randomised controlled trial (RCT) $(159$ polyps $<1 \mathrm{~cm}$ in 70 patients) examining hot versus cold snaring of polyps in anticoagulated patients, the rate of immediate haemorrhage in the hot snare versus the cold snare group was $23.0 \%$ vs $5.7 \%$, respectively, and that of delayed haemorrhage requiring intervention $14 \%$ vs $0 \%$, respectively. ${ }^{7}$ These findings should be considered in the context that polyps have been found at colonoscopy in $22.5-32.1 \%$ of patients in large studies ${ }^{8} 9$ and up to $42 \%$ in a bowel cancer screening programme, ${ }^{10}$ many will be greater than
$1 \mathrm{~cm}$ in size, and the rates of haemorrhage in the latter study above were greater than the $0.07-1.7 \%$ overall rates of haemorrhage reported in non-anticoagulated patients. ${ }^{9}{ }^{11-14}$ Routine discontinuation of warfarin therapy may therefore be considered necessary in most colonoscopy services. Even when temporarily discontinued, warfarin therapy is associated with an increased risk of post-polypectomy bleeding (PPB) ${ }^{15}$ and patients should be advised of this.

For patients with non-valvular atrial fibrillation (AF), bridging of warfarin therapy with LMWH has not been recommended in previous guidelines. ${ }^{2} 16$ This policy has been tested in a large RCT of 1884 AF patients with peri-operative interruption of warfarin therapy, randomised to bridging with LMWH or placebo. ${ }^{17}$ Approximately half of these patients underwent endoscopic procedures. In the placebo group, there was no increase in thrombotic events, but in the heparin group there was an increase in major bleeding events. Both groups included patients with $\mathrm{AF}$ and mitral stenosis (MS) or $\mathrm{CHADS}_{2}{ }^{18}$ scores of 5 or 6 , situations considered at high risk of thrombotic events. The proportion of these patients was however low $(\leq 2 \%$ for MS and $\leq 3.4 \%$ for $\mathrm{CHADS}_{2} 5,6$ ), and the study was not designed for this subgroup analysis. AF with MS is considered particularly high risk for thromboembolic events ${ }^{19} 20$ and remains in this category for these guidelines. There are insufficient data to make specific recommendations for patients with high $\mathrm{CHADS}_{2}$ scores undergoing endoscopy.

Retrospective studies of LMWH bridging for metal heart valves have suggested that this practice is safe with regard to thrombotic risk. ${ }^{21-23}$ Intravenous unfractionated heparin (UFH) is an alternative, and local cardiological advice may influence which is preferred. Bridging with UFH does, however, require a prolonged inpatient stay as warfarin is discontinued, and then restarted, to achieve satisfactory INR. Comparison of LMWH versus UFH for bridging for metal heart valves found no difference in adverse events between the groups in a multicentre registry study. ${ }^{24}$

Some patients with a personal or family history of venous thrombosis are found to have identifiable laboratory evidence of a predisposition, so called thrombophilia. In most cases the risk of venous thrombosis if anticoagulation is temporarily interrupted is not substantially different in patients with and without such abnormalities. Therefore, a thrombophilia does not indicate a high-risk condition per se and bridging with LMWH is not indicated when warfarin is interrupted. Factor V Leiden and the common prothrombin mutation F2G20210A are low-risk thrombophilias and bridging is not required. Patients with deficiencies of antithrombin, protein $\mathrm{C}$ or protein $\mathrm{S}$ are at higher risk of thrombosis, but in most of these patients bridging therapy will not be required. Thrombophilia syndromes have therefore been reclassified as low-risk conditions for the purposes of these guidelines, but we suggest that haematological advice is sought in these cases.

Apart from reclassification of the risk of thrombophilia, no new data were found to alter the recommendations for the use of warfarin or heparin stipulated in the 2008 BSG guidelines. ${ }^{2}$ Evidence was reviewed in its entirety and recommendations re-classified using GRADE.

\subsection{ANTIPLATELET AGENTS}

For all endoscopic procedures we recommend continuing aspirin (moderate evidence, strong recommendation), with the exception of ESD, large colonic EMR (>2 cm), upper gastrointestinal EMR and ampullectomy. In the latter cases, aspirin discontinuation should be considered on an individual patient 
basis depending on the risks of thrombosis versus haemorrhage (low quality evidence, weak recommendation).

For high-risk endoscopic procedures in patients at low thrombotic risk, we recommend discontinuing $\mathrm{P} 2 \mathrm{Y} 12$ receptor antagonists (eg, clopidogrel) five days before the procedure (moderate quality evidence, strong recommendation). In patients on dual antiplatelet therapy, we suggest continuing aspirin (low quality evidence, weak recommendation).

For high-risk endoscopic procedures in patients at high thrombotic risk, we recommend continuing aspirin and liaising with a cardiologist about the risk/benefit of discontinuing P2Y12 receptor antagonists (eg, clopidogrel) (bigh quality evidence, strong recommendation).

\subsection{Aspirin}

Aspirin is standard of care in patients with ischaemic heart disease. It reduces the mortality associated with acute myocardial infarction (MI) as well as the risk of fatal and non-fatal recurrent $\mathrm{MI}$ in patients with unstable coronary syndromes. It also reduces mortality and recurrent stroke in patients with acute cerebrovascular ischaemia. When given as long-term secondary prevention aspirin reduces vascular events by approximately one-third and vascular deaths by about one-sixth. Intra-platelet pathways can still be activated even in the presence of aspirin. Most patients who have suffered an acute coronary event will therefore be on dual anti-platelet therapy (DAPT), that is, aspirin plus an inhibitor of the P2Y12 receptor, either clopidogrel, prasugrel or ticagrelor.

In the context of endoscopy, aspirin monotherapy has been found to be safe in colonoscopic polypectomy and endoscopic sphincterotomy. ${ }^{25-28}$ Studies of aspirin in the context of $\mathrm{ESD}^{29} 30$ or large $(>20 \mathrm{~mm})$ colonic EMRs ${ }^{31-33}$ have found an increased risk of haemorrhage; EMR in the upper gastrointestinal tract confers a high risk of haemorrhage, but there are no studies on continuous aspirin therapy. The thrombotic risk to the patient should also be considered, particularly in those receiving aspirin for secondary prevention as they are at greater risk from discontinuation of therapy than those taking it for primary prevention. In patients on long-term low-dose aspirin for secondary prevention, aspirin interruption was associated with a three-fold increased risk of cardiovascular or cerebrovascular events, and 70\% of these events occurred within 710 days after interruption. ${ }^{34} 35$ In an RCT of 220 patients on low-dose aspirin for secondary prevention undergoing noncardiac surgery, patients were randomised to continuation or temporary replacement of aspirin by placebo $(-7$ to +3 days after surgery). ${ }^{36}$ Major cardiac events occurred within 30 days in $1.8 \%$ of the aspirin group compared to $9 \%$ in the placebo group $(p=0.02)$. No difference in bleeding complications was seen between the two groups.

Haemorrhage secondary to high-risk endoscopic procedures can often be controlled by further endoscopic therapeutic measures, and is rarely fatal. A thrombotic stroke may result in lifelong disability, and a major cardiac event may result in death. The risks of thrombosis versus haemorrhage need to be assessed on an individual patient basis, and caution should be exercised if discontinuing aspirin when prescribed for secondary prevention of ischaemic or thrombotic events.

\subsection{Clopidogrel}

The interlinked processes of platelet deposition, adherence, and aggregation are central to the initiation of the process of thrombus formation in the arterial system. The trigger is arterial wall injury, either spontaneous with an acute plaque event (rupture or erosion) as in acute coronary syndromes (ACS) (ST-segment Elevation Myocardial Infarction: STEMI or non N-STEMI: N-STEMI), or when angioplasty and stenting are used to treat coronary narrowings. Uncontrolled activation of platelets when stent struts are still exposed can lead to occlusive thrombus and heart attack.

Clopidogrel is an inhibitor of ADP-induced platelet aggregation. ${ }^{37}$ Clopidogrel plus aspirin is more effective than aspirin alone at attenuating clinical events in acute, platelet-initiated, presentations. ${ }^{38}$ DAPT has a specific and critical role in preventing occlusion of coronary artery stents. Angioplasty and stenting is the standard of care for specific sub-groups of patients with stable angina, and is the default strategy in the vast majority of patients with ACS. Like that of aspirin, the antiplatelet action of clopidogrel is irreversible and platelet function has been demonstrated to return to normal 5-7 days after withdrawal of clopidogrel, based on the regenerative production of clopidogrel-naive platelets. ${ }^{39}$

\subsection{Newer APAs}

\subsubsection{Prasugrel and ticagrelor}

Newer, more potent and more rapidly acting agents than clopidogrel have become the standard of care in patients with ACS. The two new agents now available are prasugrel and ticagrelor. Prasugrel is a thienopyridine, like clopidogrel, whereas ticagrelor is a different class of agent and reversible. Prasugrel tends to be used in selected STEMI patients, ticagrelor in both STEMI and N-STEMI ACS patients as recommended by NICE in the UK. ${ }^{40}$ Both are recommended to be continued for 12 months after discharge, in combination with aspirin. Aspirin is continued for life thereafter.

\subsubsection{Vorapaxar}

Vorapaxar is the first of a new class of APA; it is a protease-activated receptor (PAR-1) antagonist that inhibits thrombin. It is indicated for preventing cardiovascular events in patients with a history of MI or peripheral arterial disease, and it is administered in addition to aspirin or DAPT. ${ }^{41-43}$ It is contraindicated in patients with a previous history of stroke, transient ischaemic attack or intracranial haemorrhage due to an increased risk of intracranial haemorrhage. Vorapaxar was approved by the US Food and Drug Administration in 2014, and by the European Medicines Agency in 2015. There are no data on the perioperative or peri-endoscopic use of this drug, and specific recommendations have not been made at this time. Peri-endoscopic management of patients on this drug should be in consultation with a cardiologist or other specialist in cardiovascular disease.

\subsection{Ischaemic heart disease and coronary artery stents}

Patients with ischaemic heart disease are generally treated with antiplatelet therapy rather than anticoagulant therapy. Coronary artery stenting has increasingly become the dominant therapy for treating patients with coronary artery disease. Most of the exponential increase in the use of these drugs has been due to treating patients for ACS. Patients who have undergone revascularisation therapy with coronary artery surgery will tend to be prescribed aspirin alone, while those treated with stents for stable angina are generally treated with aspirin and clopidogrel for 12 months and then aspirin indefinitely. If they have had an episode of unstable angina with a troponin release they will be treated with the more rapidly acting and more potent, newer, agents, either prasugrel or ticagrelor. Therefore, unless a patient has presented with stable angina and has been treated with a bare metal stent (a minority of patients), they are likely according to current guidance to be 
treated for 12 months with either clopidogrel or one of the more potent P2Y12 inhibitors as part of their DAPT regimen.

To prevent stent thrombosis DAPT is prescribed for 12 months after drug-eluting stent (DES) deployment while bare metal stents, which are used in $<10 \%$ of cases, require a minimum of 1 month DAPT. Following DAPT, lifetime aspirin should be prescribed for both types of stent.

DAPT that is, aspirin plus either clopidogrel, prasugrel or ticagrelor also increases the risk of bleeding, ${ }^{44-46}$ either spontaneously or when a non-cardiac interventional procedure is required: clopidogrel $>$ aspirin alone, ticagrelor plus aspirin $>$ clopidogrel plus aspirin and prasugrel plus aspirin $>$ any of the other combinations although direct head to head studies comparing prasugrel with ticagrelor have not been reported.

\subsection{Clinical consequences of DAPT}

If patients develop dyspepsia on low-dose aspirin, or in any patient at risk from gastro-intestinal bleeding, co-prescription of a proton pump inhibitor should be considered initially. Failing that, and after discussion with a cardiologist, the patient taking aspirin alone could be given clopidogrel instead.

Should the patient spontaneously bleed or require a noncardiac operative procedure within the recommended time period of DAPT administration, it may seem obvious to stop the DAPT but the clinical risks associated with stopping antiplatelet therapy are high. In one study which examined factors associated with stent thrombosis, discontinuation of therapy was associated with a HR of 161 for death and MI. ${ }^{47}$ Development of stent thrombosis carries an approximate risk of $40 \%$ for MI and death. The risk of stent thrombosis increases after 5 days without antiplatelet therapy; if clopidogrel needs to be temporarily stopped in the context of an acute gastro-intestinal haemorrhage then discontinuation of therapy should be limited to this interval.

Issues related to the need to consider discontinuation of DAPT for non-cardiac surgical procedures are complex and dependent on a number of potentially confounding factors. ${ }^{48}$ For patients with known high risk of needing a future noncardiac surgical procedure (eg, planned future surgery for cancer) bare metal stenting will be undertaken because DAPT will only be required for 1 month. However this is valid for patients stented for stable conditions only since ACS patients currently still need 12 months DAPT. The variables around stent type and clinical indication, timing of need for non-cardiac operation and or bleeding make conversations with the interventional cardiologist imperative.

\subsection{Developments in antiplatelet therapy}

These include:

1. The introduction of the newer, more potent, P2Y12 inhibitors described above (prasugrel and ticagrelor);

2. The reversibility of one of these (ticagrelor) such that discontinuation may allow for an earlier procedure than for clopidogrel and prasugrel that have irreversible effects. Although platelet inhibition starts to reverse within $48 \mathrm{~h}$ it is still recommended that if clinically feasible 5 days should be allowed to lapse;

3. Newer DES (generation 3 DES) may need DAPT absolutely for only 3-6 months. ${ }^{49}$ There are a number of on-going trials comparing short duration (3 months) versus standard duration (12 months) of DAPT administration. ${ }^{50}$

4. If the patient has received DES for ACS then the recommendations are still that the DAPT (aspirin plus either prasugrel or ticagrelor) be maintained for 12 months, irrespective of DES type;

5. If, after discussion with a cardiologist, DAPT needs to be modified for a non-cardiac procedure during the 12 months following coronary stent insertion, then only the P2Y12 inhibitor should be discontinued (for 5 days prior to the procedure) - the aspirin should be continued;

6. The situation is further complicated by recent data (DAPT trial) ${ }^{51}$ which suggests that certain patients may benefit from an extension of their DAPT till at least 30 months. This study reported fewer ischaemic events in patients receiving DAPT up till 30 months than those discontinuing at 12 months, but at the cost of a higher risk of (non-fatal) bleeding;

7. The PARIS registry ${ }^{52}$ studied a real-world population of 5000 patients, and provided insight into the outcomes from physician-recommended discontinuation of DAPT, or brief interruption (for surgery), disruption (patient noncompliance), or because of bleeding. Compared with patients on continued DAPT, the adjusted HR for major adverse cardiovascular events due to interruption and disruption was $1.41(95 \% \mathrm{CI} 0.94$ to $2.12 ; \mathrm{p}=0.10)$ and 1.50 (95\% CI 1.14 to $1.97 ; \mathrm{p}=0.004)$, respectively. Within 7 days, 8-30 days, and more than 30 days after disruption, adjusted HRs were 7.04 (95\% CI 3.31 to 14.95 ), 2.17 (95\% CI 0.97 to 4.88 ), and 1.3 (95\% CI 0.97 to 1.76$)$, respectively. These data suggest that the risk of discontinuation is highest soon after stent deployment and attenuate the longer time elapsed;

8. Considering the risk associated with very early discontinuation of DAPT, patients with an early gastrointestinal haemorrhage (within the first 3 months) should be considered for endoscopic haemostasis without discontinuing DAPT.

\subsection{DIRECT ORAL ANTICOAGULANTS}

For low-risk endoscopic procedures we suggest omitting the morning dose of DOACs on the day of the procedure (very low quality evidence, weak recommendation).

For high-risk endoscopic procedures in patients on DOACs, we recommend that the last dose of DOACs be taken at least $48 \mathrm{~b}$ before the procedure. For patients on dabigatran with a $\mathrm{CrCl}$ (or eGFR) of 30-50 $\mathrm{mL} / \mathrm{min}$ we recommend that the last dose be taken $72 \mathrm{~h}$ prior to the procedure (very low quality evidence, strong recommendation). In any patient with rapidly deteriorating renal function a haematologist should be consulted (low quality evidence, strong recommendation).

\subsection{Summary}

Orally active drugs that directly inhibit thrombin (dabigatran etexilate) $^{53} 54$ and factor Xa (rivaroxaban, ${ }^{55} 56$ apixaban ${ }^{57} 58$ and edoxaban ${ }^{59}$ ) are now licensed for prevention of stroke and systemic embolus in patients with non-rheumatic AF and for prevention and treatment of deep vein thrombosis and pulmonary embolus. These drugs should not be used as anticoagulants in patients with metal heart valve prostheses. These drugs are referred to as NOACs (Non-vitamin K antagonist Oral Anti Coagulants) or DOACs (Direct Oral Anti Coagulants).

For some patients DOACs offer benefits over oral vitamin $\mathrm{K}$ antagonists (VKA) such as warfarin. The drugs are prescribed at fixed dose without the need for monitoring or dose adjustment and the rapid onset of anticoagulation and short half-life of DOACs make initiation and interruption of anticoagulation considerably easier than with VKAs. 
Specific antidotes are not yet available for clinical use, but are in development ${ }^{60-62}$ and will likely be licensed for use in the next $1-2$ years.

As with all anticoagulants produced so far there is a correlation between intensity of anticoagulation and bleeding. Consequently, the need to consider the balance of benefit and risk with a DOAC is no less important than with warfarin. When a patient taking warfarin with a known INR undergoes endoscopic biopsy the intensity of anticoagulation is quantifiable. The pharmacokinetic profile, and hence pharmacodynamic effect, of DOACs varies such that some individuals will have higher peak levels $2-6 \mathrm{~h}$ after oral administration. ${ }^{63}$ Consequently, at the time of an endoscopic biopsy the anticoagulant effect due to a DOAC is not accurately predictable. In a patient taking a DOAC the intensity of anticoagulation may be relatively high compared to the average intensity and hence until further safety data in this specific situation are available we suggest omitting the morning dose of a DOAC on the day of a low-risk procedure so that biopsies can be sampled at a trough level. In patients undergoing a high-risk procedure with a low thrombotic risk we recommend that the last dose of a DOAC is taken 2 days before the procedure, that is, no dose in the $48 \mathrm{~h}$ before the procedure. This will ensure a minimal residual anticoagulant effect in the majority of patients. All DOACs are excreted to some extent by the kidneys but dabigatran pharmacokinetics are most influenced by renal function. Therefore, dabigatran may have to be stopped for more than $48 \mathrm{~h}$ before a procedure when renal function is known to be significantly reduced. ${ }^{64}$ For patients on dabigatran with creatinine clearance $(\mathrm{CrCl})$ of $30-50 \mathrm{~mL} / \mathrm{min}$ we recommend that the drug is stopped at least $72 \mathrm{~h}$ before the procedure. Dabigatran therapy is contraindicated in patients with $\mathrm{CrCl}<30 \mathrm{~mL} / \mathrm{min}$. eGFR is a suitable alternative measurement of renal function and the same numerical values apply for the purposes of these guidelines. If a patient on any DOAC is clinically deteriorating, his/her renal function should be checked before the procedure, and if there is possible drug accumulation a quantitative measurement of DOAC intensity should be performed, for example, by calibrated anti-Xa assay for $\mathrm{Xa}$ inhibitors or Hemoclot assay for dabigatran. In patients undergoing high-risk procedures with a high thrombotic risk then advice from a haematologist is recommended. The highest thrombotic risk patients are those with mechanical heart valve prostheses but DOACs are not indicated in such patients, so patients taking DOACs will not require bridging therapy.

It is of the utmost importance that clinicians are aware that unlike reintroduction of warfarin, which results in delayed anticoagulation for several days, a therapeutic intensity of anticoagulation is restored within $3 \mathrm{~h}$ of taking a therapeutic dose of a DOAC. Because of the high risk of bleeding associated with therapeutic intensity anticoagulation after an invasive procedure, we suggest a delay in reintroducing a DOAC after a high-risk procedure. This delay will depend on the risk of haemorrhage specific to the procedure and will usually be $24-48 \mathrm{~h}$. For procedures with a significant risk of delayed haemorrhage such as EMR or ESD, a longer period of discontinuation may be considered in the context that DOAC patients are in a relatively low thrombotic risk category.

\subsection{Drug characteristics}

Compared with VKAs, DOACs are associated with a lower overall risk of major haemorrhage and particularly a significant reduction in the risk of intracranial bleeding, of the order of about a 50\% risk reduction. The incidence of gastrointestinal bleeding was, however, increased with dabigatran and rivaroxaban compared to warfarin in large RCTs, ${ }^{53} 56$ although this was confined to the elderly ( $>75$ years old) in a real-world study. ${ }^{65}$

Additional advantages of DOACs are:

- A predictable dose response;

- The absence of need for routine monitoring;

- A reduced need for dose adjustment;

- The absence of food interactions;

- Limited drug interactions.

\subsection{Dabigatran}

In the RE-LY study of patients with AF there was an increase in the rate of lower gastrointestinal bleeding in the higher dabigatran dose $\left(150 \mathrm{mg}\right.$ bd) group. ${ }^{53}$ This may be due to the low bioavailability $(6.5 \%)$ and consequent high concentrations of dabigatran in the faeces causing a local anticoagulant effect at the level of the bowel wall. ${ }^{66}$ Dyspepsia was more common with dabigatran $(11.3 \%$ and $11.8 \%$ in the 150 and $110 \mathrm{mg}$ dabigatran groups) compared with warfarin $(5.8 \%)$. The combination of higher rates of lower gastrointestinal bleeding and drug discontinuation due to dyspepsia may be a reason to choose a different anticoagulant for patients with a history of gastrointestinal disorders.

Dabigatran reaches a peak plama concentration $3 \mathrm{~h}$ after ingestion. After multiple doses a terminal half-life of about 12$14 \mathrm{~h}$ is observed. The half-life is independent of dose, but prolonged if renal function is impaired. With $\mathrm{CrCl}$ of $80 \mathrm{~mL} / \mathrm{min}$ the half life of dabigatran is $13 \mathrm{~h}$ and it increases to $27 \mathrm{~h}$ if the $\mathrm{CrCl}$ is below $30 \mathrm{~mL} / \mathrm{min}$. The recommended dose is $150 \mathrm{mg}$ bd with a dose reduction to $110 \mathrm{mg}$ bd over the age of 80 years and in patients with a $\mathrm{CrCl}<50 \mathrm{~mL} / \mathrm{min}$. It should not be prescribed in patients with a $\mathrm{CrCl} \leq 30 \mathrm{~mL} / \mathrm{min}$. Patients with liver enzymes more than twice the upper limit of normal were excluded from the RE-LY study. Nevertheless, there is no liver toxicity associated with dabigatran and so the drug might be used as long as there is no coagulopathy associated with liver disease. Aspirin or clopidogrel should be used with caution or avoided, and non-steroidal anti-inflammatory drugs should be avoided as their concomitant use was associated with an increased bleeding risk in the RE-LY study.

\subsection{Rivaroxaban}

Rivaroxaban is a direct competitive inhibitor of factor $\mathrm{Xa}$ and limits thrombin generation in a dose dependent manner. Absorption of this drug is rapid and it presents a half-life of $7-$ $11 \mathrm{~h}$. Two thirds of rivaroxaban are metabolised in the liver but it can be used in patients with liver disease if there is no coagulopathy. Only about one third of active rivaroxaban is cleared by the kidneys and there is no accumulation of drug when the $\mathrm{CrCl}$ is above $15 \mathrm{~mL} / \mathrm{min}$. However, a dose reduction from $20 \mathrm{mg}$ once daily to $15 \mathrm{mg}$ once daily has been recommended for patients with a $\mathrm{CrCl}$ between 15 and $30 \mathrm{~mL} / \mathrm{min}$. Rivaroxaban is not recommended when the $\mathrm{CrCl}$ is $\leq 15 \mathrm{~mL} /$ min. As with dabigatran, lower gastrointestinal bleeding occurred more frequently in the elderly with rivaroxaban than with warfarin.

\subsection{Apixaban and edoxaban}

Apixaban and edoxaban are $\mathrm{Xa}$ inhibitors that were approved subsequently to rivaroxaban for prevention of stroke in patients with non valvular AF and for treatment and prevention of venous thrombosis. ${ }^{67}$ Less than $50 \%$ of these drugs are cleared by the kidneys and similar recommendations to those made for 
rivaroxaban apply to interruption and recommencement of these drugs.

\subsection{Measurement of anticoagulant effect of DOACs}

Measurement of the anticoagulant effect of DOACs may be required when a patient is bleeding or scheduled for a high-risk intervention. Laboratories should ideally be aware of the sensitivity of their own prothrombin time (PT) and activated partial thromboplastin (APTT) assays to each drug. The result of a qualitative test such as the PT or APTT can indicate whether anticoagulation is supratherapeutic, therapeutic or subtherapeutic but cannot be used to determine the plasma concentration of the drug. The test results are dependent on when the last dose of drug was taken and therefore require interpretation with reference to the dose, anticipated half-life and factors that influence pharmacokinetics.

The Hemoclot thrombin inhibitor assay is a sensitive dabigatran-calibrated thrombin clotting time which can be used to determine the drug concentration. ${ }^{68}$ Anti-factor Xa assays are sensitive to factor Xa inhibitors. ${ }^{69-71}$ By using specific DOAC calibrators and controls, the anti-factor Xa chromogenic method is suitable for measuring a wide range of plasma concentrations of Xa inhibitors, which covers the expected plasma levels after therapeutic doses.

\subsection{Bridging therapy}

Compared to warfarin, requirement for bridging with heparin when interrupting DOACs are different due to the fast on and off effects of DOACs. In the Dresden DOAC registry heparin bridging for patients on rivaroxaban did not reduce cardiovascular events and led to a significantly higher rate of major bleeding compared to no bridging $(2.7 \%$ vs $0.5 \%, \mathrm{p}=0.01){ }^{72}$ In addition, a sub-study of the RE-LY trial found that bridging of dabigatran with $\mathrm{LMWH}$ resulted in higher rates of major bleeding $(6.5 \%$ vs $1.8 \%, \mathrm{p}<0.001)$ with no reduction in thromboembolism compared to no bridging. ${ }^{73}$

\subsection{Triple antithrombotic therapy}

Patients on dual antiplatelet therapy for coronary artery stents may develop AF requiring anticoagulation with warfarin or DOACs. Conversely, patients anticoagulated for chronic AF may develop ACSs requiring dual antiplatelet therapy. Consensus guidelines have been produced for the management of these situations, ${ }^{74}$ but patients on triple antithrombotic therapy have a high risk of haemorrhage and caution is advised. ${ }^{75} 76$ There are no data on endoscopy in these patients and advice should be sought from a cardiologist, or other relevant specialist such as a stroke physician, if endoscopy is essential.

\subsection{Management of bleeding patients treated with DOACs}

Management depends on the severity of bleeding. When bleeding is not severe, temporary drug withdrawal may be the only requirement due to the short half-lives of these drugs. For more severe bleeding general treatment measures may be required and consideration should be given to general resuscitation interventions, including endoscopic haemostasis, fluid replacement, correction of anaemia by transfusion of red cells and correction of additional coagulopathy (eg, dilutional coagulopathy) with platelet transfusion and appropriate blood products. The time of last intake of DOAC should be determined and the half-life can be estimated from measurement of serum creatinine and calculation of the $\mathrm{CrCl}$. The anticoagulant activity of the DOAC should be determined by the most appropriate laboratory assay.
Protamine sulfate and vitamin $\mathrm{K}$ have no effect on the anticoagulant effects of DOACs. The effect of antifibrinolytics on bleeding due to DOACs is not known but use of tranexamic acid would be reasonable in some patients. Similarly, the general haemostatic effect of desmopressin (DDAVP) independent of thrombin or factor $\mathrm{Xa}$ might be beneficial although this is unknown. Fresh frozen plasma does not reverse the anticoagulant effect of DOACs to any appreciable degree and no clinical benefit has been demonstrated. The effects of prothrombin complex concentrate (PCC) and recombinant factor VIIa (rVIIa) have not been studied in clinical trials in human patients with bleeding. The effect of rivaroxaban on coagulation tests from volunteers is reversed by PCC (50 IU/ kg of 4-factor concentrate) but the effect of dabigatran is not. ${ }^{77}$ These results do not indicate one way or the other if PCCs would reduce clinical bleeding. For patients with life-threatening bleeding, administration of $40-50 \mathrm{IU} / \mathrm{kg}$ of PCC has been suggested but there is no clinical evidence as yet that this will reduce clinical bleeding. ${ }^{78} 79$

\subsection{ENDOSCOPIC PROCEDURES: RISK OF HAEMORRHAGE}

There is an intrinsic risk of haemorrhage associated with endoscopic procedures. Minor haemorrhage is not uncommon during therapeutic endoscopic procedures, but we have considered it to be clinically significant when haemoglobin value falls by more than $20 \mathrm{~g} / \mathrm{L}$, necessitates blood transfusion or causes an unplanned hospital admission. Haemorrhage may be immediately apparent at the time of endoscopy, or delayed up to two weeks following the procedure. The latter situation may present a higher risk for patients who are on antiplatelet therapy or anticoagulants following the procedure. It is important that, not only are patients advised of the risks of haemorrhage following endoscopic procedures, but that they are given written advice on how to seek appropriate medical help should this occur following discharge from hospital. Unless otherwise stated, the following sections review the risks of haemorrhage in patients who are not on antithrombotic therapy, and these data are subsequently used to stratify the risk of procedures (table 1).

\subsection{Diagnostic endoscopy and mucosal biopsy}

Diagnostic endoscopies, including mucosal biopsy sampling, harbour a minimal risk of haemorrhage, and no severe haemorrhage has been reported in studies involving thousands of patients in total. ${ }^{9}{ }^{80-83}$ Furthermore no increased risk of haemorrhage from biopsy has been found in studies of patients on aspirin, clopidogrel or warfarin. ${ }^{84} 85$ In these studies only small numbers of biopsies were taken, and the safety of taking large numbers of biopsies in patients on warfarin, such as in Barrett's oesophagus surveillance, has not been studied. There have been no published reports of excess bleeding in this context, however. There are no data about biopsies in patients taking the newer APAs or DOACs. Due to uncertainty regarding the level of anticoagulation on DOACs at the time of endoscopy and the absence of reliable test of anticoagulation on these drugs, we suggest omitting the dose of DOAC on the morning of the procedure to allow an adequate safety margin. This applies to both once daily and twice daily regimens.

\subsection{Post polypectomy bleeding}

Published haemorrhage rates for polypectomy, EMR or ESD are confounded by heterogeneity of definitions of intra-procedural bleeding (IPB) and PPB between studies. Previous studies of colonoscopic polypectomy have identified a risk of PPB of $0.07-1.7 \% .^{9}{ }^{11-14}$ In a BSG audit of 20085 colonoscopies in the UK, $52(0.26 \%)$ haemorrhages were reported. ${ }^{8}$ Thirty nine 
of these were self-limited, three $(0.01 \%)$ required transfusion, and one required surgery. Data from the English National Bowel Cancer Screening Programme on 112024 participants, of whom 69028 underwent polypectomy, found an overall PPB rate of $1.14 \% .{ }^{86}$ Polypectomy increased the risk of bleeding by a factor of 11.14 compared with no polypectomy. In large series (>1000 polypectomies), ${ }^{86-92}$ delayed PPB varied from 0.6 to $2.2 \%$ and the mean time to onset of bleeding was 4.0 \pm 2.9 days. $^{92}$ It is important to differentiate between minor haemorrhage associated with polypectomy which is controlled at the time of the procedure and more significant haemorrhage which requires an unplanned admission to hospital, possibly with repeat endoscopy and/or transfusion. The incidence of severe bleeding requiring transfusion in the English Bowel Cancer Screening Programme was $0.08 \% .^{86}$

Polyp size is the most consistent risk factor for colonic PPB, and it has been calculated that every $1-\mathrm{mm}$ increase in polyp diameter increases the risk of PPB by $9 \% .{ }^{93}$ Use of pure cutting current was found to be an independent predictive factor of immediate PPB compared with blended or coagulation current in a large cohort of 5152 patients undergoing more than 9000 polypectomies (OR, 6.95; 95\% CI 4.42 to 10.94$).{ }^{94}$ In a prospective cohort study, the use of a non microprocessorcontrolled current was an independent predictive factor of delayed bleeding when performing a wide field EMR. ${ }^{32}$ Two recent meta-analyses have examined data on RCTs for PPB prophylaxis. ${ }^{95} 96$ In the first, the seven studies included a majority of pedunculated large polyps (range, 14 to $26 \mathrm{~mm}$ ) and the primary outcome focused on the overall risk of PPB. ${ }^{95}$ The authors found that any of the prophylactic measures helped prevent PPB (RR, 0.32; 95\% CI 0.20 to 0.52), and mechanical techniques (detachable loop or endoclip) were superior to submucosal injection of diluted adrenaline (RR, 0.28; 95\% CI 0.14 to 0.57). Submucosal injection of adrenaline was, however, found to reduce the risk of overall PPB when compared to no treatment or saline injection alone (RR, 0.37; 95\% CI 0.20 to 0.66). The second meta-analysis evaluated the impact of endoscopic prophylactic methods on early PPB (within the first $24 \mathrm{~h}){ }^{96}$ Diluted adrenaline injection reduced significantly the risk of early PPB (OR, 0.37; 95\% CI 0.22 to 0.64 ) as well as any other single prophylactic modality. No significant difference was observed between endoclip and detachable snare in a recent multicentre RCT to prevent delayed PPB in patients with pedunculated polyps with a large stalk $(\geq 10 \mathrm{~mm})(5.1 \%$ vs $5.7 \%$, respectively). ${ }^{97}$ One RCT showed no significant difference in delayed PPB when using clips for pedunculated polyps, and the study was closed prematurely due to complications: one perforation $(1.5 \%)$ and 3 mucosal burns (4.5\%). ${ }^{98}$ This result could be explained by the incorrect placement of the clip in $10 / 66$ patients $(15 \%)$ with a short stalk, resulting in thermal injury due to the contact between the snare and the clip at the base of the pedicle. In all of these studies, patients on antiplatelet therapy or anticoagulation were excluded.

\subsubsection{Endoscopic mucosal resection}

Several studies have examined the prophylactic effect of endoclips on delayed PPB for sessile colonic polyps. ${ }^{99-101}$ One RCT of post-EMR defect closure by endoclips compared to no intervention failed to demonstrate any significant benefit. ${ }^{101}$ The study was however under-powered for this outcome. Two other studies of prophylaxis of PPB included antiplatelet therapy and/ or anticoagulation users (47\% and $10 \%$, respectively). ${ }^{99} 100$ Pooled analysis showed a reduction of delayed PPB if the EMR defect was closed using endoclips (1.8\% vs $4.4 \%)$ with an OR of 0.40 (95\% CI 0.20 to 0.80$)$, especially for large ( $\geq 20 \mathrm{~mm})$ polyps. Furthermore a recent cost-efficacy analysis concluded that prophylactic placement of endoscopic clips after polypectomy was a cost-effective strategy for patients receiving antiplatelet or anticoagulation therapy, but not otherwise. ${ }^{102}$ For duodenal EMR, the use of endoclips to close the defect was recently found to significantly reduce the risk of delayed bleeding in a recent retrospective study (7\% vs $32 \%) .{ }^{103}$ A large multicentre RCT found no reduction in significant post-EMR bleeding using prophylactic soft coagulation with forceps on visible vessels compared to no endoscopic prophylaxis. ${ }^{31}$

In large (>1000 cases) series of EMR, the incidence of immediate and delayed bleeding ranged between $3.7-11.3 \%$ and $0.6-$ $6.2 \%$, respectively. ${ }^{32} 104105$ which are higher rates than those reported after conventional polypectomy. For EMR of small lesions $(<10 \mathrm{~mm})$, however, PPB rates were similar to those reported following conventional polypectomy. ${ }^{105}$ In two thirds of the patients, delayed bleeding developed within $48 \mathrm{~h}$ of colonic EMR. ${ }^{32}$ In one study, oesophageal EMR presented a greater risk of IPB compared with duodenal or colonic EMR. ${ }^{106}$ Nevertheless the rate of delayed post-EMR bleeding in the oesophagus remains low $(0.6-0.9 \%)$, even in studies that include a high proportion of patients with a temporary cessation of antiplatelet therapy. ${ }^{106} 107$ Duodenal EMR had the highest risk of delayed bleeding. In two retrospective observational studies of duodenal EMR, delayed bleeding was reported in 14/ $113(12.3 \%)^{103}$ and $7 / 111$ patients $(6.3 \%)^{106}$ despite the prophylactic use of endoclips in $82 \%$ of cases in the latter.

\subsubsection{Endoscopic submucosal dissection}

Compared with EMR, ESD presents a higher procedure-related bleeding rates irrespective to the location of the lesion treated (OR, 2.20; 95\% CI 1.58 to 3.07). ${ }^{108}$ This is mostly a problem in the stomach; the mean rate of post procedural bleeding across five recent large studies (>6000 patients in total) of gastric ESD was 5.8\% (range 3.6-6.9\%). ${ }^{30} 109-113$ Nevertheless, severe consequences were rare (1 death, 3 angiographic interventions, and no surgery). In the oesophagus, a recent meta-analysis of 15 studies provided a pooled estimate of post-ESD delayed bleeding of only $2.1 \%$ (95\% CI $1.2 \%$ to $3.8 \%){ }^{114}$ With respect to colonic ESD, a systematic review (total, 2774 patients) found a bleeding rate of $2 \%$ (95\% CI $1 \%$ to $2 \%) .{ }^{115}$ No bleeding-related mortality was noted in oesophageal or colonic studies. A large multicentre prospective Japanese register confirmed this low rate of post colorectal ESD bleeding with only $18 / 816$ events $(2.2 \%) .{ }^{116}$ A higher bleeding rate was reported by a small prospective European study $(6 / 45,13 \%),{ }^{117}$ though this included only rectal lesions, which present a higher risk of delayed bleeding. ${ }^{118} 119$

\subsubsection{Polypectomy on antithrombotic therapy}

A meta-analysis studied the risk of PPB in patients on continued clopidogrel therapy (574 patients and 6169 controls). ${ }^{120}$ Polyp size was less than $10 \mathrm{~mm}$ in $88 \%$ of the cases, and the proportion of patients on DAPT ranged from $54 \%$ to $87.8 \% .^{121-123}$ There was an overall increased risk of PPB (RR, 2.54; 95\% CI 1.68 to 3.84) and of delayed PPB (RR, 4.66; 95\% CI 2.37 to 9.17). Nevertheless, no patients required surgical or angiographic intervention and there were no fatalities. Another meta-analysis that included five studies demonstrated an increased risk of delayed but not immediate PPB on clopidogrel. ${ }^{120}$

A prospective study including 823 patients focused on cold polypectomy (using forceps or snare method) with a mean polyp size of $4.7 \pm 1.3 \mathrm{~mm}^{91} ; 15 \%$ of the patients were taking low dose 
aspirin or ticlopidine. The risk of immediate PPB was increased in patients on continued APAs $(6.2 \%$ vs $1.4 \%$; $<<0.001)$ but all bleeding episodes were successfully treated during the procedure, and no delayed PPB was observed. No data on PPB in patients taking prasugrel, ticagrelor, or DOACs were found.

The impact of APAs on colonic post-EMR bleeding was evaluated in two recent prospective observational studies and one RCT comparing endoscopic prophylactic coagulation of visible vessels compared to no prophylaxis for wide field EMR $(>2 \mathrm{~cm}) .^{31-33}$ Pooled analysis of the results in 1807 patients showed that clinically significant post-EMR bleeding was associated with the use of aspirin; only 20 patients were on clopidogrel so that no conclusion can be drawn for clopidogrel. No data are available regarding the use of prasugrel, ticagrelor or DOACs in relation to colonic EMR.

There are no studies of the risk of bleeding on continuous anti platelet therapy for oesophageal or duodenal EMR. Two retrospective observational studies found no relation between previous APA use including clopidogrel (stopped 5-7 days before the procedure) and the occurrence of early or delayed bleeding. ${ }^{106} 107$ Caution is required if aspirin therapy is interrupted when prescribed for secondary prophylaxis due to the high risk of thrombotic events. ${ }^{34-36}$

The association of thienopyridene or aspirin use with the risk of post-ESD bleeding has been examined in several studies of gastric ESD. These studies are, however, retrospective single-centre case studies with a variety of APAs, and differences in regimens for discontinuing or continuing therapy. Bleeding end-points also vary between studies. Aspirin was an independent risk factor for haemorrhage in one study, ${ }^{29}$ and in two others there was an increased risk of post-ESD haemorrhage despite temporary interruption of antiplatelet therapy. ${ }^{30} 109$ Recent dual therapy with aspirin and clopidogrel was an independent predictive factor for delayed bleeding (OR >10 in two studies), ${ }^{29}{ }^{124}$ but continued use of low dose aspirin alone, ${ }^{125}$ or after temporary discontinuation of thiopyridene, was not found to be an independent risk factor for post-ESD bleeding in other studies. ${ }^{110} 126127$ Insufficient data were available to interpret the role of clopidogrel alone on post-ESD bleeding, and the numbers of patients on aspirin monotherapy in the above studies was small. Two studies have reported no association between post-ESD bleeding and antithrombotic agents for colorectal ESD, but the drugs were discontinued 1 week before the procedure. ${ }^{118} 119$ No data on APA therapy and oesophageal ESD were found. No data are available regarding the use of prasugrel, ticagrelor or DOACs in relation to ESD.

\subsection{Endoscopic retrograde cholangiopancreatography}

Reviews of endoscopic retrograde cholangiopancreatography (ERCP) practice have found that clinically significant haemorrhage occurs in $0.1-2 \%$ of sphincterotomies. ${ }^{128} 129$ Risk factors for haemorrhage after biliary sphincterotomy included bleeding observed during the procedure, coagulopathy, initiation of anticoagulant therapy within 3 days after the procedure, active cholangitis, and low endoscopist case volume of endoscopic sphincterotomies. For endoscopic sphincterotomy, blended current, as opposed to pure-cutting current, is recommended as a meta-analysis of RCTs demonstrated that it reduces the incidence of post-sphincterotomy haemorrhage without significantly increasing the risk of post-ERCP pancreatitis. ${ }^{130} 131$

To decrease the risk of bleeding, endoscopic papillary balloon dilation (EPBD) has been proposed as an alternative to sphincterotomy for biliary stone extraction. A recent meta-analysis that included 12 RCTs (1975 patients) concluded that, compared with endoscopic sphincterotomy, EPBD was associated with a lower incidence of haemorrhage, a lower rate of stone clearance, and a higher incidence of post-ERCP pancreatitis. ${ }^{132}$ However another meta-analysis of RCTs demonstrated that prolonged $(>1 \mathrm{~min})$ EPBD actually reduced the incidence of post-ERCP pancreatitis (compared to short EPBD) to a level similar to that observed with sphincterotomy. ${ }^{133}$ As bleeding rates were lower with EPBD versus sphincterotomy, in a network meta-analysis, the probabilities of being the safest treatment for long EPBD/ short $\mathrm{EPBD} /$ sphincterotomy regarding overall complications were $90.3 \% / 1.3 \% / 8.4 \%$, respectively. ${ }^{13}$ Therefore, if EPBD is performed without sphincterotomy, balloon inflation should be maintained $\geq 1 \mathrm{~min}$ following waist disappearence. Usual contraindications to EPBD include biliary strictures, ampullary/pancreatic/biliary malignancies, prior biliary surgery except cholecystectomy, acute pancreatitis, precut sphincterotomy for biliary access and large common bile duct (CBD) stones.

Finally, sphincterotomy is not required for most placements of biliary plastic stents or self-expanding metal stents (SEMS). A meta-analysis of three RCTs (338 patients) that compared patients with sphincterotomy before biliary stent placement compared to without endoscopic sphincterotomy found that sphincterotomy was associated with a higher incidence of post-ERCP haemorrhage $(6.2 \%$ vs 0$)$ but a lower incidence of post-ERCP pancreatitis $(3.5 \%$ vs $8.9 \%) .{ }^{134}$ The rate of stent migration was similar in both groups of patients. A large prospective nonrandomised study that compared patients with stent placement preceded or not by sphincterotomy ( $\mathrm{n}=130$ vs 1112 , respectively) found that stent insertion was successful in all patients, with similar incidences of post-ERCP pancreatitis and bleeding in both groups of patients. ${ }^{135}$

\subsubsection{ERCP on antithrombotic therapy}

Five controlled studies of biliary sphincterotomy in patients receiving APA were found ${ }^{129}{ }^{136-139}$; only one of them reported a statistically significant difference in haemorrhage in APA users $(9.6 \%)$ versus non-users $(3.9 \%)$. This study was retrospective and the difference was not significant in multivariate analysis. In addition to these studies, a retrospective study compared 40 patients with post-sphincterotomy bleeding vs 86 matched controls who had no post-sphincterotomy bleeding; similar proportions of patients taking APA were found among both groups of patients (13\% aspirin and 3\% clopidogrel vs $17 \%$ aspirin and $0 \%$ clopidogrel in cases vs controls, respectively). ${ }^{140}$

Endoscopic sphincterotomy followed by large balloon dilation is increasingly undertaken for large biliary stone extraction; haemorrhage has been reported in $0-8.6 \%$ of patients. ${ }^{141} \mathrm{~A}$ single series was identified that included five patients taking aspirin at the time of endoscopic sphincterotomy followed by large balloon dilation; none of them presented with significant bleeding. ${ }^{142}$ There are no data on this technique in patients on thienopyridines, ticagrelor or DOAC.

There are no data on biliary mechanical lithotripsy in patients taking APA or anticoagulants. Similarly there are no data on cholangioscopy and electrohydraulic lithotripsy therapy on these drugs.

\subsection{Ampullectomy}

Endoscopic ampullectomy is an established technique for resection of ampullary adenomas, and this is generally followed by pancreatic duct stenting at ERCP to reduce the risk of postprocedure pancreatitis. ${ }^{143}$ The risk of haemorrhage following ampullectomy ranges from $1 \%$ to $7 \%$ in published series. ${ }^{144-147}$ No study was found that reported on endoscopic ampullectomy in patients taking aspirin or other antithrombotic agents. Some 
authors have stated that aspirin can be continued in patients at high thrombotic risk ${ }^{148}$ but this should be assessed on an individual patient basis, as bleeding is a common complication and may be severe.

\subsection{Endoscopic ultrasound-guided fine-needle aspiration}

The incidence of bleeding following endoscopic ultrasoundguided fine-needle aspiration (EUS-FNA) has been analysed in a systematic review that included 10941 patients (51 studies); globally the incidence of bleeding was 1.28 per thousand ${ }^{149}$ Incidences per site, per thousand, were, in increasing order: pancreas 1 (pancreatic mass, 0.7; pancreatic cyst, 3.3), mediastinum 1.5, perirectal lesion 5.2, liver 8.7, ascites 11.8. EUS-guided brushing of pancreatic cysts was associated with a relatively high incidence of bleeding in five prospective studies, including one fatality. ${ }^{150-154}$

One prospective study assessed the risk of bleeding complicating EUS-FNA in patients taking aspirin/NSAIDs. ${ }^{155}$ In this study, 241 lesions were sampled, including solid tumours, cysts and ascites with a mean of approximately 2.5 passes using a $19 \mathrm{G}$ or $22 \mathrm{G}$ needle. There was no significant difference in bleeding between those taking aspirin/NSAIDs (0 of 26 patients) compared with controls (7 of 190 patients). There are no studies identified that assessed haemorrhage after EUS-FNA in patients taking thienopyridines, ticagrelor or DOAC.

\subsection{Endoscopic dilatation and stenting}

\subsubsection{Dilatation}

Large studies of bougie-dilatation of oesophageal strictures reported no significant haemorrhage. ${ }^{156} 157$ Controlled radial expansion balloons are more commonly used for this purpose now. A study of 472 oesophageal dilations included a mixture of bougie and balloon dilatations, and no perforations or haemorrhage were reported, ${ }^{158}$ A series of 98 balloon dilations of anastomotic strictures of the cervical oesophagus reported no haemorrhagic complications. ${ }^{159}$ A study of the complications arising from 504 balloon dilations in 237 patients with achalasia revealed $4(1.7 \%)$ asymptomatic haematomas, but no clinically significant haemorrhage. ${ }^{160}$ There were, however, 7 (3\%) perforations. Seven case series have reported no haemorrhages following ileal or colonic dilation. ${ }^{161-166}$ Two further case series did however report haemorrhage associated with dilation of ileal or colonic strictures in $1 / 20(5 \%)^{167}$ and $1 / 38(2.6 \%)$ patients. $^{168}$ One study included dilation of malignant strictures and encountered no haemorrhagic complication in 94 cases (68 malignant and 26 anastomotic strictures). ${ }^{169}$ In a RCT of pneumatic dilatation versus laparoscopic myotomy for achalasia there were no reported haemorrhages but 8/108 $(9.5 \%)$ patients experienced perforation during the treatment course. ${ }^{170}$ None of the abovementioned studies was primarily designed to evaluate the risk of bleeding associated with dilation. There have been no studies evaluating the risk of endoscopic dilatation in the gastrointestinal tract in patients taking APA or anticoagulants.

\subsubsection{Endoscopic stent insertion}

Historical studies of complications associated with endoscopic stenting may be confounded by the variety of stents employed and the improvements in devices with time. There have been no studies on endoscopic stenting at any site in the gastrointestinal tract in patients taking APA or anticoagulants. A US national survey of oesophageal SEMS insertion reported a haemorrhagic complication rate of $0.5 \%(2 / 434) .{ }^{171} \mathrm{~A}$ haemorrhage rate of $1 \%$ was found in a retrospective study of 92 oesophageal stent placements. ${ }^{172}$ In two studies of oesophageal stenting for palliation of malignant strictures, fatal haemorrhage occurred in $7.3 \%{ }^{173}$ and $8 \%$ of patients. ${ }^{174}$ Haemorrhage was however delayed in these series, often by several weeks. Comparative studies of various types of self-expanding oesophageal stents reported similar rates of efficacy and complications. ${ }^{175-180}$ Immediate haemorrhage rates are low, but consideration should be given to delayed severe haemorrhage, and this is likely to be a particular risk in patients on APA or anticoagulant therapy.

A systematic review of duodenal stenting included 606 patients in whom $3(0.5 \%)$ haemorrhages were reported. ${ }^{181}$ An international multicentre prospective cohort study conducted between 1996 and $2003^{182}$ assessed the efficacy and safety of enteral stents: 188 stents were placed in 176 patients and 2 (1\%) of them suffered from gastrointestinal haemorrhage.

With respect to colorectal stenting, a systematic review of 58 studies (598 patients) ${ }^{183}$ found a bleeding rate of $4.5 \%$. Twenty-four (89\%) haemorrhages required no treatment, but the $3(0.5 \%)$ remaining patients had severe haemorrhage requiring blood transfusion. A systematic review of 27 studies involving 325 patients with malignant colonic obstruction did not report any cases of gastrointestinal haemorrhage. ${ }^{184} \mathrm{~A}$ third systematic review that included 54 publications, none of which were randomised, found no cases of gastrointestinal haemorrhage in 1192 patients- ${ }^{185}$ A retrospective study of 102 stent placements revealed no haemorrhages, but 4 (4\%) perforations, ${ }^{186}$ and a multicentre prospective study of 44 stent placements revealed one case of haematoma which resolved spontaneously, and no perforations. ${ }^{187}$ In a study of 463 colonic stent placements in 447 patients, there were only $2(0.5 \%)$ cases of haemorrhage, but 15 (3.9\%) perforations, 3 of which were fatal. ${ }^{188}$ In a RCT of colonic stenting versus emergency surgery in the context of acute malignant colonic obstruction there were no instances of haemorrhage in the stenting group, but $6 / 47$ (13\%) perforations. ${ }^{189}$

\subsection{Percutaneous endoscopic gastrostomy}

Minor haemorrhage around the wound site at percutaneous endoscopic gastrostomy (PEG) placement is not uncommon and usually ceases spontaneously or with simple pressure at the wound site. Severe haemorrhage is rare, but may occur due to vascular puncture. ${ }^{190} 191$ Rectus sheath haematoma has also been described. ${ }^{192}$ Continued administration of aspirin for PEG placement has not been associated with an increased risk of haemorrhage. ${ }^{193}$ Additionally, there was no increased risk of haemorhage on clopidogrel in a retrospective single-centre casecontrol study of 990 patients, ${ }^{194}$ although this study was statistically underpowered to demonstrate an effect due to this drug. There have been no studies examining the risk of PEG placement in patients on prasugrel, ticagrelor or DOAC.

\subsection{Device-assisted enteroscopy}

Single-balloon, double-balloon and spiral enteroscopy devices are commonly used. The overall risk of haemorrhage associated with double balloon enteroscopy has been estimated at $0.2 \%,{ }^{195}$ and rises to $3.3 \%$ if polypectomy is performed. ${ }^{195}$ Spiral enteroscopy has not been associated with a risk of clinically significant haemorrhage. ${ }^{196}$ Double balloon enteroscopy is associated with a perforation rate of $0.1-0.4 \% 0^{195} 197$ and this rises to $1.5 \%$ if polypectomy is performed ${ }^{197}$ and $3 \%$ in patients with an altered surgical anatomy. ${ }^{195}$ There have been no studies examining the risks of enteroscopy in patients taking APA or anticoagulants.

\subsection{Oesophageal variceal banding}

Emergency variceal banding occurs in the context of active variceal haemorrhage, which is a life-threatening emergency. 
Table 4 Risk assessment matrix of haemorrhagic and thrombotic risk

\begin{tabular}{|c|c|c|c|c|}
\hline & \multicolumn{2}{|c|}{ Risk of endoscopic procedure haemorrhage } & \multicolumn{2}{|l|}{ Risk of thrombosis } \\
\hline & Low risk & High risk & Low risk & High risk \\
\hline \multicolumn{5}{|l|}{ Aspirin } \\
\hline Continue & Biopsy $0 \%{ }^{84}$ & $\begin{array}{l}\text { Standard risk of procedure, except large colonic } \\
\text { EMR } 6.2-7 \% \%^{32}{ }^{33} \text { with 'recent' LDA. } \\
\text { Gastric ESD increased risk on LDA to } 21.1 \%^{29} \text { vs } \\
\text { no increased risk } 15.5 \% \%^{124}\end{array}$ & $0.51 \%$ per year $\%{ }^{203}$ & $1.8 \%$ at 30 days $^{36}$ \\
\hline Discontinue 7 days & N/A & Standard risk of procedure & Estimate $<1 \%$ per year & $9 \%$ at 30 days $^{36}$ \\
\hline \multicolumn{5}{|l|}{ Warfarin } \\
\hline Continue & Biopsy $0 \%{ }^{84}$ & Polypectomy $0.8-23 \%{ }^{67}$ & $<1 \%$ per year ${ }^{204}$ & $1 \%$ per year $^{205}$ \\
\hline Discontinue 5 days & N/A & Standard risk of procedure; increased PPB risk ${ }^{15}$ & AF $0.4 \%$ at 30 days $^{17}$ & $\mathrm{~N} / \mathrm{A}$ \\
\hline Bridge with LMWH & N/A & Standard risk of procedure; increased PPB risk ${ }^{15}$ & AF $0.3 \%$ at 30 days $^{17}$ & Metal heart valves $0 \% 2223$ \\
\hline \multicolumn{5}{|l|}{ Dual APA } \\
\hline Continue & Biopsy $0 \%{ }^{84} 85$ & Polypectomy $<1 \mathrm{~cm} 2.1-6.45 \%{ }^{120} 121$ & $\mathrm{~N} / \mathrm{A}$ & $1.3 \%$ at 9 months ${ }^{47}$ \\
\hline $\begin{array}{l}\text { Discontinue } \\
5 \text { days }\end{array}$ & N/A & Estimate standard risk of procedure & $\mathrm{N} / \mathrm{A}$ & Not advised \\
\hline \multicolumn{5}{|l|}{ DOAC } \\
\hline Omit day of procedure & No specific data & $\mathrm{N} / \mathrm{A}$ & No specific data & DOAC not indicated \\
\hline $\begin{array}{l}\text { Discontinue } \\
48 \mathrm{~h}\end{array}$ & $\mathrm{~N} / \mathrm{A}$ & No specific data & $0.8 \%^{72}$ & DOAC not indicated \\
\hline
\end{tabular}

Elective variceal banding is also associated with a risk of delayed haemorrhage. In a study of 605 patients undergoing variceal ligation, $21(3.5 \%)$ patients had spontaneous bleeding due to band slippages confirmed at endoscopy, and 11 died. ${ }^{198}$ Rebleeding due to band-induced ulcers has been found to occur in up to $14 \%$ of patients. ${ }^{199-202}$ Multivariate analysis in the first study found no increased risk of bleeding in those on aspirin, although this applied to only 8/605 patients. ${ }^{198}$ There have been no studies of the risks of haemorrhage following variceal banding in patients on thienopyridenes, ticagrelor or DOAC, and indeed it would be usual to discontinue these drugs, if possible, in a population at such a high risk of haemorrhage.

\subsection{ENDOSCOPY ON APA AND ANTICOAGULANTS: RISK STRATIFICATION}

Certain endoscopic procedures carry a higher risk of haemorrhage, and certain clinical situations will result in a high risk of thromboembolic complications should APA or anticoagulants be withdrawn. Procedures have been classified as high-risk or low-risk for haemorrhage based on baseline risks of haemorrhage or perforation associated with the procedures as well as the limited data available regarding endoscopy during therapy with APA or anticoagulants (table 1). Tables 2 and 3 stratify risk for discontinuation of APA or warfarin according to clinical scenario, and the risks of thromboembolic sequelae on discontinuation of therapy. A risk assessment matrix based on these factors is shown in table 4.

Diagnostic endoscopic procedures, with or without biopsy, are classified as low-risk for haemorrhage. This applies to diagnostic colonoscopy, but polyps are likely to be encountered in $22.5-34.2 \%$ of patients according to large studies, ${ }^{9}{ }^{11}$ and endoscopists may therefore choose to manage colonoscopies as high-risk procedures with respect to APA and anticoagulants including DOAC. Similar considerations apply to ERCP if there is uncertainty as to the required therapy.

\section{Author affiliations}

${ }^{1}$ Department of Gastroenterology, New Cross Hospital, Wolverhampton, UK
${ }^{2}$ Department of Gastroenterology, Hôpital Universitaire L'Archet 2, Nice Cedex 3, France

${ }^{3}$ Department of Cardiovascular Sciences, University Hospitals of Leicester, Glenfield Hospital, Leicester, UK

${ }^{4}$ Service Unité Endoscopie Digestive, Hopital Saint Joseph, Marseille, France

${ }^{5}$ Department of Haematology, Addenbrookes Hospital, Cambridge, UK

${ }^{6}$ Department of Gastroenterology, Auckland City Hospital, Auckland, New Zealand

${ }^{7}$ Unità Operativa Complessa di Gastroenterologia, Servizio di Endoscopia Digestiva, Ospedale Valduce, Como, Italy

${ }^{8}$ AntiCoagulation Europe, Bromley, Kent, UK

${ }^{9}$ Institute of Gastroenterology and Liver Diseases, Ha'Emek Medical Center, Afula, Israel

${ }^{10}$ Rappaport Faculty of Medicine Technion, Israel Institute of Technology, Israel

${ }^{11}$ Digestive Endoscopy Unit, Catholic University, Rome, Italy

${ }^{12}$ Gedyt Endoscopy Center, Buenos Aires, Argentina

Contributors All authors have contributed to literature searches, manuscript preparation and review of previous drafts of the guidelines.

Competing interests Prof Gershlick has received lecture fees for advisory boards for Astra Zeneca and Eli Lilley/Daiichi Sankyo. None of the other authors have competing interests to declare.

Provenance and peer review Not commissioned; externally peer reviewed.

Disclaimer These joint BSG and ESGE guidelines represent a consensus of best practice based on the available evidence at the time of preparation. They may not apply in all situations and should be interpreted in the light of specific clinical situations and resource availability. Further controlled clinical studies may be needed to clarify aspects of these statements, and revision may be necessary as new data appear. Clinical consideration may justify a course of action at variance to these recommendations. BSG and ESGE guidelines are intended to be an educational device to provide information that may assist endoscopists in providing care to patients. They are not rules and should not be construed as establishing a legal standard of care or as encouraging, advocating, requiring, or discouraging any particular treatment.

Open Access This is an Open Access article distributed in accordance with the Creative Commons Attribution Non Commercial (CC BY-NC 4.0) license, which permits others to distribute, remix, adapt, build upon this work non-commercially, and license their derivative works on different terms, provided the original work is properly cited and the use is non-commercial. See: http://creativecommons.org/ licenses/by-nc/4.0/

\section{REFERENCES}

1 Gralnek IM, Dumonceau JM, Kuipers EJ, et al. Diagnosis and management of nonvariceal upper gastrointestinal hemorrhage: European Society of Gastrointestinal Endoscopy (ESGE) Guideline. Endoscopy 2015;47:a1-46. 
2 Veitch AM, Baglin TP, Gershlick AH, et al. Guidelines for the management of anticoagulant and antiplatelet therapy in patients undergoing endoscopic procedures. Gut 2008;57:1322-9.

3 Boustière C, Veitch A, Vanbiervliet G, et al. Endoscopy and antiplatelet agents. European Society of Gastrointestinal Endoscopy (ESGE) Guideline. Endoscopy 2011:43:445-61.

4 Agree Next Steps Consortium. The AGREE II Instrument (Electronic version), 2009. http://www.agreetrust.org

5 Guyatt GH, Oxman AD, Vist GE, et al. GRADE: an emerging consensus on rating quality of evidence and strength of recommendations. BMJ 2008;336:924-6.

6 Friedland S, Sedehi D, Soetikno R. Colonoscopic polypectomy in anticoagulated patients. World J Gastroenterol NICE 2009;15:1973-6.

7 Horiuchi A, Nakayama Y, Kajiyama M, et al. Removal of small colorectal polyps in anticoagulated patients: a prospective randomized comparison of cold snare and conventional polypectomy. Gastrointest Endosc 2014;79:417-23.

8 Gavin DR, Valori RM, Anderson JT, et al. The national colonoscopy audit: a nationwide assessment of the quality and safety of colonoscopy in the UK. Gut 2013;62:242-9.

9 Wexner SD, Garbus JE, Singh JJ, et al. A prospective analysis of 13,580 colonoscopies. Reevaluation of credentialing guidelines. Surg Endosc 2001;15:251-61.

10 Ellul P, Fogden E, Simpson CL, et al. Downstaging of colorectal cancer by the National Bowel Cancer Screening programme in England: first round data from the first centre. Colorectal Dis 2010;12:420-2.

11 Bowles CJ, Leicester R, Romaya C, et al. A prospective study of colonoscopy practice in the UK today: are we adequately prepared for national colorectal cancer screening tomorrow? Gut 2004;53:277-83.

12 Gibbs DH, Opelka FG, Beck DE, et al. Postpolypectomy colonic hemorrhage. Dis Colon Rectum 1996;39:806-10.

13 Rosen L, Bub DS, Reed JF III, et al. Hemorrhage following colonoscopic polypectomy. Dis Colon Rectum 1993;36:1126-31.

14 Sieg A, Hachmoeller-Eisenbach U, Eisenbach T. Prospective evaluation of complications in outpatient Gl endoscopy: a survey among German gastroenterologists. Gastrointest Endosc 2001;53:620-7.

15 Witt DM, Delate T, McCool KH, et al. Incidence and predictors of bleeding or thrombosis after polypectomy in patients receiving and not receiving anticoagulation therapy. J Thromb Haemost 2009;7:1982-9.

16 Eisen GM, Baron TH, Dominitz JA, et al. Guideline on the management of anticoagulation and antiplatelet therapy for endoscopic procedures. Gastrointest Endosc 2002;55:775-9.

17 Douketis JD, Spyropoulos AC, Kaatz S, et al. Perioperative bridging anticoagulation in patients with atrial fibrillation. N Engl J Med 2015;373:823-33.

18 Gage BF, Waterman AD, Shannon W, et al. Validation of clinical classification schemes for predicting stroke: results from the National Registry of Atrial Fibrillation. JAMA 2001;285:2864-70.

19 Nishimura RA, Otto CM, Bonow RO, et al. 2014 AHA/ACC guideline for the management of patients with valvular heart disease: executive summary: a report of the American College of Cardiology/American Heart Association Task Force on Practice Guidelines. J Am Coll Cardiol 2014;63:2438-88.

20 Szekely P. Systemic Embolism and Anticoagulant Prophylaxis in Rheumatic Heart Disease. BMJ 1964;1:1209-12.

21 Meurin P, Tabet JY, Weber H, et al. Low-molecular-weight heparin as a bridging anticoagulant early after mechanical heart valve replacement. Circulation 2006;113:564-9.

22 Seshadri N, Goldhaber SZ, Elkayam U, et al. The clinical challenge of bridging anticoagulation with low-molecular-weight heparin in patients with mechanical prosthetic heart valves: an evidence-based comparative review focusing on anticoagulation options in pregnant and nonpregnant patients. Am Heart $J$ 2005; 150:27-34.

23 Shapira Y, Sagie A, Battler A. Low-molecular-weight heparin for the treatment of patients with mechanical heart valves. Clin Cardiol 2002;25:323-7.

24 Spyropoulos AC, Turpie AG, Dunn AS, et al. Perioperative bridging therapy with unfractionated heparin or low-molecular-weight heparin in patients with mechanical prosthetic heart valves on long-term oral anticoagulants (from the REGIMEN Registry). Am J Cardiol 2008;102:883-9.

25 Hui AJ, Wong RM, Ching JY, et al. Risk of colonoscopic polypectomy bleeding with anticoagulants and antiplatelet agents: analysis of 1657 cases. Gastrointest Endosc 2004;59:44-8.

26 Nelson DB, Freeman ML. Major hemorrhage from endoscopic sphincterotomy: risk factor analysis. J Clin Gastroenterol 1994;19:283-7.

27 Shiffman ML, Farrel MT, Yee YS. Risk of bleeding after endoscopic biopsy or polypectomy in patients taking aspirin or other NSAIDS. Gastrointest Endosc 1994;40:458-62.

28 Yousfi M, Gostout CJ, Baron TH, et al. Postpolypectomy lower gastrointestinal bleeding: potential role of aspirin. Am J Gastroenterol 2004;99:1785-9.

29 Cho SJ, Choi IJ, Kim CG, et al. Aspirin use and bleeding risk after endoscopic submucosal dissection in patients with gastric neoplasms. Endoscopy 2012;44:114-21.
30 Takeuchi T, Ota K, Harada S, et al. The postoperative bleeding rate and its risk factors in patients on antithrombotic therapy who undergo gastric endoscopic submucosal dissection. BMC Gastroenterol 2013;13:136.

31 Bahin FF, Naidoo M, Williams SJ, et al. Prophylactic endoscopic coagulation to prevent bleeding after wide-field endoscopic mucosal resection of large sessile colon polyps. Clin Gastroenterol Hepatol 2015;13:724-30.e1-2.

32 Burgess NG, Metz AJ, Williams SJ, et al. Risk factors for intraprocedural and clinically significant delayed bleeding after wide-field endoscopic mucosal resection of large colonic lesions. Clin Gastroenterol Hepatol 2014;12: 651-61.e1-3.

33 Metz AJ, Bourke MJ, Moss A, et al. Factors that predict bleeding following endoscopic mucosal resection of large colonic lesions. Endoscopy 2011:43:506-11.

34 Biondi-Zoccai GG, Lotrionte $\mathrm{M}$, Agostoni P, et al. A systematic review and meta-analysis on the hazards of discontinuing or not adhering to aspirin among 50,279 patients at risk for coronary artery disease. Eur Heart J 2006;27:2667-74.

35 Maulaz $A B$, Bezerra DC, Michel $P$, et al. Effect of discontinuing aspirin therapy on the risk of brain ischemic stroke. Arch Neurol 2005;62:1217-20.

36 Oscarsson A, Gupta A, Fredrikson M, et al. To continue or discontinue aspirin in the perioperative period: a randomized, controlled clinical trial. $\mathrm{Br} J$ Anaesth 2010:104:305-12.

37 Geiger J, Brich J, Honig-Liedl P, et al. Specific impairment of human platelet P2Y (AC) ADP receptor-mediated signaling by the antiplatelet drug clopidogrel. Arterioscler Thromb Vasc Biol 1999;19:2007-11.

38 Budaj A, Yusuf S, Mehta SR, et al. Benefit of clopidogrel in patients with acute coronary syndromes without ST-segment elevation in various risk groups. Circulation 2002;106:1622-6.

39 Korte W, Cattaneo M, Chassot PG, et al. Peri-operative management of antiplatelet therapy in patients with coronary artery disease: joint position paper by members of the working group on Perioperative Haemostasis of the Society on Thrombosis and Haemostasis Research (GTH), the working group on Perioperative Coagulation of the Austrian Society for Anesthesiology, Resuscitation and Intensive Care (ÖGARI) and the Working Group Thrombosis of the European Society for Cardiology (ESC). Thromb Haemost 2011;105:743-9.

40 NICE. Myocardial infarction with ST-segment elevation: the acute management of myocardial infarction with ST-segment elevation. 2013.

41 Bonaca MP, Scirica BM, Braunwald E, et al. Coronary stent thrombosis with vorapaxar versus placebo: results from the TRA $2^{\circ}$ P-TIMI 50 trial. J Am Coll Cardiol 2014;64:2309-17.

42 Magnani G, Bonaca MP, Braunwald E, et al. Efficacy and safety of vorapaxar as approved for clinical use in the United States. J Am Heart Assoc 2015;4: e001505.

43 Morrow DA, Braunwald E, Bonaca MP, et al. Vorapaxar in the secondary prevention of atherothrombotic events. $N$ Engl J Med 2012;366:1404-13.

44 Wallentin L, Becker RC, Budaj A, et al. Ticagrelor versus clopidogrel in patients with acute coronary syndromes. N Engl J Med 2009;361:1045-57.

45 Wiviott SD, Braunwald E, McCabe $\mathrm{CH}$, et al. Prasugrel versus clopidogrel in patients with acute coronary syndromes. N Engl J Med 2007;357:

2001-15.

46 Zeymer U, Hochadel M, Lauer B, et al. Use, efficacy and safety of prasugrel in patients with ST segment elevation myocardial infarction scheduled for primary percutaneous coronary intervention in clinical practice. Results of the prospective ATACS-registry. Int J Cardiol 2015;184:122-7.

47 lakovou I, Schmidt T, Bonizzoni E, et al. Incidence, predictors, and outcome of thrombosis after successful implantation of drug-eluting stents. JAMA 2005;293:2126-30.

48 Gershlick AH, Richardson G. Drug eluting stents. BMJ 2006;333:1233-4.

49 Stone GW, Midei M, Newman W, et al. Randomized comparison of everolimus-eluting and paclitaxel-eluting stents: two-year clinical follow-up from the Clinical Evaluation of the Xience V Everolimus Eluting Coronary Stent System in the Treatment of Patients with de novo Native Coronary Artery Lesions (SPIRIT) III trial. Circulation 2009;119:680-6.

50 Feres F, Costa RA, Abizaid A, et al. Three vs twelve months of dual antiplatelet therapy after zotarolimus-eluting stents: the OPTIMIZE randomized trial. JAMA 2013;310:2510-22.

51 Kereiakes DJ, Yeh RW, Massaro JM, et al. Antiplatelet therapy duration following bare metal or drug-eluting coronary stents: the dual antiplatelet therapy randomized clinical trial. JAMA 2015;313:1113-21.

52 Mehran R, Baber U, Steg PG, et al. Cessation of dual antiplatelet treatment and cardiac events after percutaneous coronary intervention (PARIS): 2 year results from a prospective observational study. Lancet 2013;382:1714-22.

53 Connolly SJ, Ezekowitz MD, Yusuf S, et al. Dabigatran versus warfarin in patients with atrial fibrillation. N Engl J Med 2009;361:1139-51.

54 Schulman S, Kearon C, Kakkar AK, et al. Dabigatran versus warfarin in the treatment of acute venous thromboembolism. N Engl J Med 2009;361: 2342-52. 
55 Bauersachs R, Berkowitz SD, Brenner B, et al. Oral rivaroxaban for symptomatic venous thromboembolism. N Engl J Med 2010;363:2499-510.

56 Patel MR, Mahaffey KW, Garg J, et al. Rivaroxaban versus warfarin in nonvalvular atrial fibrillation. N Engl J Med 2011;365:883-91.

57 Agnelli G, Buller HR, Cohen A, et al. Oral apixaban for the treatment of acute venous thromboembolism. N Engl J Med 2013;369:799-808.

58 Granger $\mathrm{CB}$, Alexander JH, McMurray JJ, et al. Apixaban versus warfarin in patients with atrial fibrillation. N Engl J Med 2011;365:981-92.

59 Giugliano RP, Ruff $\mathrm{CT}$, Braunwald E, et al. Edoxaban versus warfarin in patients with atrial fibrillation. N Engl J Med 2013;369:2093-104.

60 Ansell JE, Bakhru SH, Laulicht BE, et al. Use of PER977 to reverse the anticoagulant effect of edoxaban. N Engl J Med 2014;371:2141-2.

61 Lu G, DeGuzman FR, Hollenbach SJ, et al. A specific antidote for reversal of anticoagulation by direct and indirect inhibitors of coagulation factor Xa. Nat Med 2013:19:446-51.

62 Pollack CV Jr, Reilly PA, Eikelboom J, et al. Idarucizumab for Dabigatran Reversal. N Engl J Med 2015;373:511-20.

63 Baglin T. Clinical use of new oral anticoagulant drugs: dabigatran and rivaroxaban. Br J Haematol 2013:163:160-7.

64 Schulman S, Carrier M, Lee AY, et al. Perioperative Management of Dabigatran: A Prospective Cohort Study. Circulation 2015;132:167-73.

65 Abraham NS, Singh S, Alexander GC, et al. Comparative risk of gastrointestinal bleeding with dabigatran, rivaroxaban, and warfarin: population based cohort study. BMJ 2015;350:h1857.

66 Blech S, Ebner T, Ludwig-Schwellinger E, et al. The metabolism and disposition of the oral direct thrombin inhibitor, dabigatran, in humans. Drug Metab Dispos 2008;36:386-99.

67 van Es N, Coppens M, Schulman S, et al. Direct oral anticoagulants compared with vitamin $\mathrm{K}$ antagonists for acute venous thromboembolism: evidence from phase 3 trials. Blood 2014;124:1968-75.

68 Stangier J, Feuring M. Using the HEMOCLOT direct thrombin inhibitor assay to determine plasma concentrations of dabigatran. Blood Coagul Fibrinolysis 2012;23:138-43

69 Asmis LM, Alberio L, Angelillo-Scherrer A, et al. Rivaroxaban: quantification by anti-FXa assay and influence on coagulation tests: a study in 9 Swiss laboratories. Thromb Res 2012;129:492-8

70 Samama MM, Contant G, Spiro TE, et al. Evaluation of the anti-factor Xa chromogenic assay for the measurement of rivaroxaban plasma concentrations using calibrators and controls. Thromb Haemost 2012:107:379-87.

71 Samama MM, Martinoli JL, LeFlem L, et al. Assessment of laboratory assays to measure rivaroxaban-an oral, direct factor Xa inhibitor. Thromb Haemost 2010;103:815-25.

72 Beyer-Westendorf J, Gelbricht V, Förster K, et al. Peri-interventional management of novel oral anticoagulants in daily care: results from the prospective Dresden NOAC registry. Eur Heart J 2014;35:1888-96.

73 Douketis JD, Healey JS, Brueckmann M, et al. Perioperative bridging anticoagulation during dabigatran or warfarin interruption among patients who had an elective surgery or procedure. Substudy of the RE-LY trial. Thromb Haemost 2015;113:625-32.

74 Lip GY, Huber K, Andreotti F, et al. Antithrombotic management of atrial fibrillation patients presenting with acute coronary syndrome and/or undergoing coronary stenting: executive summary - $a$ Consensus Document of the European Society of Cardiology Working Group on Thrombosis, endorsed by the European Heart Rhythm Association (EHRA) and the European Association of Percutaneous Cardiovascular Interventions (EAPCI). Eur Heart J 2010:31:1311-18.

75 Dewilde WJ, Janssen PW, Verheugt FW, et al. Triple therapy for atrial fibrillation and percutaneous coronary intervention: a contemporary review. J Am Coll Cardiol 2014:64:1270-80

76 Rubboli A, Agewall S, Huber K, et al. New-onset atrial fibrillation after recent coronary stenting: Warfarin or non-vitamin $\mathrm{K}$-antagonist oral anticoagulants to be added to aspirin and clopidogrel? A viewpoint. Int I Cardiol 2015;196:133-8.

77 Eerenberg ES, Kamphuisen PW, Sijpkens MK, et al. Reversal of rivaroxaban and dabigatran by prothrombin complex concentrate: a randomized, placebo-controlled, crossover study in healthy subjects. Circulation 2011;124:1573-9.

78 Schulman S, Crowther MA. How I treat with anticoagulants in 2012: new and old anticoagulants, and when and how to switch. Blood 2012;119:3016-23.

79 Weitz JI, Quinlan DJ, Eikelboom JW. Periprocedural management and approach to bleeding in patients taking dabigatran. Circulation 2012;126:2428-32.

80 Cappell MS, Abdullah M. Management of gastrointestinal bleeding induced by gastrointestinal endoscopy. Gastroenterol Clin North Am 2000;29:125-67, vi-vii.

81 Macrae FA, Tan KG, Williams CB. Towards safer colonoscopy: a report on the complications of 5000 diagnostic or therapeutic colonoscopies. Gut 1983;24:376-83.

82 Rogers BH, Silvis SE, Nebel OT, et al. Complications of flexible fiberoptic colonoscopy and polypectomy. Gastrointest Endosc 1975;22:73-7.

83 Vu CK, Korman MG, Bejer I, et al. Gastrointestinal bleeding after cold biopsy. Am J Gastroenterol 1998:93:1141-3.
84 Ono S, Fujishiro M, Kodashima S, et al. Evaluation of safety of endoscopic biopsy without cessation of antithrombotic agents in Japan. J Gastroenterol 2012;47:770-4.

85 Whitson MJ, Dikman AE, von Althann C, et al. Is gastroduodenal biopsy safe in patients receiving aspirin and clopidogrel?: a prospective, randomized study involving 630 biopsies. J Clin Gastroenterol 2011;45:228-33.

86 Rutter MD, Nickerson C, Rees CJ, et al. Risk factors for adverse events related to polypectomy in the English Bowel Cancer Screening Programme. Endoscopy 2014:46:90-7

87 Choung BS, Kim SH, Ahn DS, et al. Incidence and risk factors of delayed postpolypectomy bleeding: a retrospective cohort study. I Clin Gastroenterol 2014:48:784-9.

88 Gimeno-García AZ, de Ganzo ZA, Sosa AJ, et al. Incidence and predictors of postpolypectomy bleeding in colorectal polyps larger than $10 \mathrm{~mm}$. Eur J Gastroenterol Hepatol 2012;24:520-6.

$89 \mathrm{Kim} \mathrm{JH}$, Lee HJ, Ahn JW, et al. Risk factors for delayed post-polypectomy hemorrhage: a case-control study. J Gastroenterol Hepatol 2013;28:645-9.

90 Manocha $\mathrm{D}$, Singh $\mathrm{M}$, Mehta $\mathrm{N}$, et al. Bleeding risk after invasive procedures in aspirin/NSAID users: polypectomy study in veterans. Am J Med 2012;125: $1222-7$

91 Repici A, Hassan C, Vitetta E, et al. Safety of cold polypectomy for $<10 \mathrm{~mm}$ polyps at colonoscopy: a prospective multicenter study. Endoscopy 2012;44: 27-31.

92 Zhang Q, An S, Chen Z, et al. Assessment of risk factors for delayed colonic post-polypectomy hemorrhage: a study of 15553 polypectomies from 2005 to 2013. PLOS ONE 2014:9:e108290.

93 Sawhney MS, Salfiti N, Nelson DB, et al. Risk factors for severe delayed postpolypectomy bleeding. Endoscopy 2008:40:115-19.

$94 \mathrm{Kim}$ HS, Kim TI, Kim WH, et al. Risk factors for immediate postpolypectomy bleeding of the colon: a multicenter study. Am J Gastroenterol 2006;101:1333-41.

95 Corte CJ, Burger DC, Horgan G, et al. Postpolypectomy haemorrhage following removal of large polyps using mechanical haemostasis or epinephrine: a meta-analysis. United European Gastroenterol I 2014;2:123-30.

96 Li LY, Liu QS, Li L, et al. A meta-analysis and systematic review of prophylactic endoscopic treatments for postpolypectomy bleeding. Int I Colorectal Dis 2011;26:709-19.

97 Ji JS, Lee SW, Kim TH, et al. Comparison of prophylactic clip and endoloop application for the prevention of postpolypectomy bleeding in pedunculated colonic polyps: a prospective, randomized, multicenter study. Endoscopy 2014;46:598-604.

98 Quintanilla E, Castro JL, Rábago LR, et al. Is the use of prophylactic hemoclips in the endoscopic resection of large pedunculated polyps useful? A prospective and randomized study. I Interv Gastroenterol 2012;2:183-8

99 Liaquat H, Rohn E, Rex DK. Prophylactic clip closure reduced the risk of delayed postpolypectomy hemorrhage: experience in 277 clipped large sessile or flat colorectal lesions and 247 control lesions. Gastrointest Endosc 2013;77:401-7.

100 Feagins $L A$, Nguyen $A D$, lqbal $R$, et al. The prophylactic placement of hemoclips to prevent delayed post-polypectomy bleeding: an unnecessary practice? A case control study. Dig Dis Sci 2014;59:823-8.

101 Shioji K, Suzuki Y, Kobayashi M, et al. Prophylactic clip application does not decrease delayed bleeding after colonoscopic polypectomy. Gastrointest Endosc 2003:57:691-4.

102 Parikh ND, Zanocco K, Keswani RN, et al. A cost-efficacy decision analysis of prophylactic clip placement after endoscopic removal of large polyps. Clin Gastroenterol Hepatol 2013;11:1319-24.

103 Nonaka S, Oda I, Tada K, et al. Clinical outcome of endoscopic resection for nonampullary duodenal tumors. Endoscopy 2015;47:129-35.

104 Cipolletta L, Rotondano G, Bianco MA, et al. Endoscopic resection for superficia colorectal neoplasia in Italy: a prospective multicentre study. Dig Liver Dis 2014:46:146-51.

105 Heresbach D, Kornhauser R, Seyrig JA, et al. A national survey of endoscopic mucosal resection for superficial gastrointestinal neoplasia. Endoscopy 2010;42:806-13.

106 Qumseya BJ, Wolfsen C, Wang Y, et al. Factors associated with increased bleeding post-endoscopic mucosal resection. J Dig Dis 2013;14:140-6.

107 Namasivayam V, Prasad GA, Lutzke LS, et al. The risk of endoscopic mucosal resection in the setting of clopidogrel use. ISRN Gastroenterol 2014;2014:494157.

108 Cao Y, Liao C, Tan A, et al. Meta-analysis of endoscopic submucosal dissection versus endoscopic mucosal resection for tumors of the gastrointestinal tract. Endoscopy 2009;41:751-7.

109 Koh R, Hirasawa K, Yahara S, et al. Antithrombotic drugs are risk factors for delayed postoperative bleeding after endoscopic submucosal dissection for gastric neoplasms. Gastrointest Endosc 2013;78:476-83.

$110 \mathrm{Lim} \mathrm{JH}$, Kim SG, Kim JW, et al. Do antiplatelets increase the risk of bleeding after endoscopic submucosal dissection of gastric neoplasms? Gastrointest Endosc 2012;75:719-27. 
111 Miyahara K, Iwakiri R, Shimoda R, et al. Perforation and postoperative bleeding of endoscopic submucosal dissection in gastric tumors: analysis of 1190 lesions in low- and high-volume centers in Saga, Japan. Digestion 2012;86:273-80.

112 Toyokawa T, Inaba T, Omote $\mathrm{S}$, et al. Risk factors for perforation and delayed bleeding associated with endoscopic submucosal dissection for early gastric neoplasms: analysis of 1123 lesions. J Gastroenterol Hepatol 2012;27: 907-12.

113 Toyonaga T, Man-i M, East JE, et al. 1,635 Endoscopic submucosal dissection cases in the esophagus, stomach, and colorectum: complication rates and long-term outcomes. Surg Endosc 2013;27:1000-8.

114 Kim JS, Kim BW, Shin IS. Efficacy and safety of endoscopic submucosal dissection for superficial squamous esophageal neoplasia: a meta-analysis. Dig Dis Sci 2014;59:1862-9.

115 Repici A, Hassan C, De Paula Pessoa D, et al. Efficacy and safety of endoscopic submucosal dissection for colorectal neoplasia: a systematic review. Endoscopy 2012;44:137-50.

116 Nakajima T, Saito Y, Tanaka S, et al. Current status of endoscopic resection strategy for large, early colorectal neoplasia in Japan. Surg Endosc 2013:27:3262-70.

117 Rahmi G, Hotayt B, Chaussade S, et al. Endoscopic submucosal dissection for superficial rectal tumors: prospective evaluation in France. Endoscopy 2014:46:670-6.

118 Terasaki M, Tanaka S, Shigita K, et al. Risk factors for delayed bleeding after endoscopic submucosal dissection for colorectal neoplasms. Int J Colorectal Dis 2014;29:877-82.

119 Suzuki S, Chino A, Kishihara T, et al. Risk factors for bleeding after endoscopic submucosal dissection of colorectal neoplasms. World J Gastroenterol 2014:20:1839-45

120 Gandhi S, Narula N, Mosleh W, et al. Meta-analysis: colonoscopic post-polypectomy bleeding in patients on continued clopidogrel therapy. Aliment Pharmacol Ther 2013;37:947-52.

121 Singh M, Mehta N, Murthy UK, et al. Postpolypectomy bleeding in patients undergoing colonoscopy on uninterrupted clopidogrel therapy. Gastrointest Endosc 2010;71:998-1005.

122 Feagins LA, Iqbal $R$, Harford WV, et al. Low rate of postpolypectomy bleeding among patients who continue thienopyridine therapy during colonoscopy. Clin Gastroenterol Hepatol 2013;11:1325-32.

123 Feagins LA, Uddin FS, Davila RE, et al. The rate of post-polypectomy bleeding for patients on uninterrupted clopidogrel therapy during elective colonoscopy is acceptably low. Dig Dis Sci 2011;56:2631-8.

124 Tounou S, Morita Y, Hosono T. Continuous aspirin use does not increase post-endoscopic dissection bleeding risk for gastric neoplasms in patients on antiplatelet therapy. Endosc Int Open 2015;3:E31-8.

125 Sanomura Y, Oka S, Tanaka S, et al. Continued use of low-dose aspirin does not increase the risk of bleeding during or after endoscopic submucosal dissection for early gastric cancer. Gastric Cancer 2014;17:489-96.

126 Matsumura T, Arai M, Maruoka D, et al. Risk factors for early and delayed post-operative bleeding after endoscopic submucosal dissection of gastric neoplasms, including patients with continued use of antithrombotic agents. BMC Gastroenterol 2014;14:172.

127 Nakamura M, Nishikawa J, Hamabe K, et al. Risk factors for delayed bleeding from endoscopic submucosal dissection of gastric neoplasms. Scand J Gastroenterol 2012;47:1108-14.

128 Cotton PB, Lehman G, Vennes J, et al. Endoscopic sphincterotomy complications and their management: an attempt at consensus. Gastrointest Endosc 1991;37:383-93.

129 Freeman ML, Nelson DB, Sherman S, et al. Complications of endoscopic biliary sphincterotomy. N Engl J Med 1996;335:909-18.

130 Rey JF, Beilenhoff U, Neumann CS, et al. European Society of Gastrointestinal Endoscopy (ESGE) guideline: the use of electrosurgical units. Endoscopy 2010:42:764-72

131 Verma D, Kapadia A, Adler DG. Pure versus mixed electrosurgical current for endoscopic biliary sphincterotomy: a meta-analysis of adverse outcomes. Gastrointest Endosc 2007:66:283-90.

132 Zhao HC, He L, Zhou DC, et al. Meta-analysis comparison of endoscopic papillary balloon dilatation and endoscopic sphincteropapillotomy. World J Gastroenterol 2013;19:3883-91

133 Liao WC, Tu YK, Wu MS, et al. Balloon dilation with adequate duration is safer than sphincterotomy for extracting bile duct stones: a systematic review and meta-analyses. Clin Gastroenterol Hepatol 2012;10:1101-9.

134 Cui PJ, Yao J, Zhao YJ, et al. Biliary stenting with or without sphincterotomy for malignant biliary obstruction: a meta-analysis. World J Gastroenterol 2014:20:14033-9.

135 Wilcox CM, Kim H, Ramesh J, et al. Biliary sphincterotomy is not required for bile duct stent placement. Dig Endosc 2014;26:87-92.

136 Hui CK, Lai KC, Yuen MF, et al. Does withholding aspirin for one week reduce the risk of post-sphincterotomy bleeding? Aliment Pharmacol Ther 2002;16:929-36.
137 Lee MG, Kim J, Lee SH, et al. Effect of sustained use of platelet aggregation inhibitors on post-endoscopic sphincterotomy bleeding. Dig Endosc 2014; 26:737-44.

138 Onal IK, Parlak E, Akdogan M, et al. Do aspirin and non-steroidal anti-inflammatory drugs increase the risk of post-sphincterotomy hemorrhage-a case-control study. Clin Res Hepatol Gastroenterol 2013;37:171-6.

139 Patai A, Solymosi N, Patai AV. Does rectal indomethacin given for prevention of post-ERCP pancreatitis increase bleeding after biliary endoscopic sphincterotomy or cardiovascular mortality?: Post hoc analysis using prospective clinical trial data. Medicine (Baltimore) 2014;93:e159.

140 Hussain N, Alsulaiman R, Burtin P, et al. The safety of endoscopic sphincterotomy in patients receiving antiplatelet agents: a case-control study. Aliment Pharmacol Ther 2007;25:579-84.

141 Rouquette 0, Bommelaer G, Abergel A, et al. Large balloon dilation post endoscopic sphincterotomy in removal of difficult common bile duct stones: a literature review. World J Gastroenterol 2014;20:7760-6.

142 Poincloux L, Rouquette 0, Privat J, et al. Large-balloon dilation of the sphincter of Oddi after sphincterotomy or infundibulotomy to extract large calculi or multiple common bile duct stones without using mechanical lithotripsy. Scand J Gastroenterol 2013;48:246-51.

143 Harewood GC, Pochron NL, Gostout CJ. Prospective, randomized, controlled trial of prophylactic pancreatic stent placement for endoscopic snare excision of the duodenal ampulla. Gastrointest Endosc 2005;62:367-70.

144 Bohnacker S, Seitz U, Nguyen D, et al. Endoscopic resection of benign tumors of the duodenal papilla without and with intraductal growth. Gastrointest Endosc 2005:62:551-60.

145 Catalano MF, Linder JD, Chak A, et al. Endoscopic management of adenoma of the major duodenal papilla. Gastrointest Endosc 2004;59:225-32.

146 Cheng CL, Sherman S, Fogel EL, et al. Endoscopic snare papillectomy for tumors of the duodenal papillae. Gastrointest Endosc 2004;60:757-64.

147 Irani S, Arai A, Ayub K, et al. Papillectomy for ampullary neoplasm: results of a single referral center over a 10-year period. Gastrointest Endosc 2009;70: 923-32.

148 Bassan M, Bourke M. Endoscopic ampullectomy: a practical guide. J Interv Gastroenterol 2012;2:23-30.

149 Wang KX, Ben QW, Jin ZD, et al. Assessment of morbidity and mortality associated with EUS-guided FNA: a systematic review. Gastrointest Endosc 2011;73:283-90.

150 Al-Haddad M, Gill KR, Raimondo M, et al. Safety and efficacy of cytology brushings versus standard fine-needle aspiration in evaluating cystic pancreatic lesions: a controlled study. Endoscopy 2010;42:127-32.

151 Bruno M, Bosco M, Carucci P, et al. Preliminary experience with a new cytology brush in EUS-guided FNA. Gastrointest Endosc 2009;70:1220-4

152 Lozano MD, Subtil JC, Miravalles TL, et al. EchoBrush may be superior to standard EUS-guided FNA in the evaluation of cystic lesions of the pancreas: preliminary experience. Cancer Cytopathol 2011;119:209-14.

153 Sendino 0, Fernández-Esparrach G, Solé M, et al. Endoscopic ultrasonography-guided brushing increases cellular diagnosis of pancreatic cysts: a prospective study. Dig Liver Dis 2010;42:877-81.

154 Thomas T, Bebb J, Mannath J, et al. EUS-guided pancreatic cyst brushing: a comparative study in a tertiary referral centre. JOP 2010;11:163-9.

155 Kien-Fong Vu C, Chang F, Doig L, et al. A prospective control study of the safety and cellular yield of EUS-guided FNA or Trucut biopsy in patients taking aspirin, nonsteroidal anti-inflammatory drugs, or prophylactic low molecular weight heparin. Gastrointest Endosc 2006:63:808-13.

156 Pereira-Lima JC, Ramires RP, Zamin I Jr, et al. Endoscopic dilation of benign esophageal strictures: report on 1043 procedures. Am J Gastroenterol 1999;94:1497-501.

157 Raymondi R, Pereira-Lima JC, Valves A, et al. Endoscopic dilation of benign esophageal strictures without fluoroscopy: experience of 2750 procedures. Hepatogastroenterology 2008;55:1342-8.

158 Polese L, Angriman I, Bonello E, et al. Endoscopic dilation of benign esophageal strictures in a surgical unit: a report on 95 cases. Surg Laparosc Endosc Percutan Tech 2007; 17:477-81.

159 Williams VA, Watson TJ, Zhovtis S, et al. Endoscopic and symptomatic assessment of anastomotic strictures following esophagectomy and cervical esophagogastrostomy. Surg Endosc 2008;22:1470-6.

160 Metman EH, Lagasse JP, d'Alteroche L, et al. Risk factors for immediate complications after progressive pneumatic dilation for achalasia. Am $J$ Gastroenterol 1999:94:1179-85.

161 Ajlouni Y, Iser JH, Gibson PR. Endoscopic balloon dilatation of intestinal strictures in Crohn's disease: safe alternative to surgery. J Gastroenterol Hepatol 2007:22:486-90.

162 Araujo SE, Costa AF. Efficacy and safety of endoscopic balloon dilation of benign anastomotic strictures after oncologic anterior rectal resection: report on 24 cases. Surg Laparosc Endosc Percutan Tech 2008;18:565-8.

163 Blomberg B, Rolny $P$, Järnerot $G$. Endoscopic treatment of anastomotic strictures in Crohn's disease. Endoscopy 1991;23:195-8. 
164 Couckuyt H, Gevers AM, Coremans G, et al. Efficacy and safety of hydrostatic balloon dilatation of ileocolonic Crohn's strictures: a prospective longterm analysis. Gut 1995;36:577-80.

165 Dear KL, Hunter JO. Colonoscopic hydrostatic balloon dilatation of Crohn's strictures. I Clin Gastroenterol 2001;33:315-18.

166 Thomas-Gibson S, Brooker JC, Hayward CM, et al. Colonoscopic balloon dilation of Crohn's strictures: a review of long-term outcomes. Eur J Gastroenterol Hepatol 2003:15:485-8.

167 Nomura E, Takagi S, Kikuchi T, et al. Efficacy and safety of endoscopic balloon dilation for Crohn's strictures. Dis Colon Rectum 2006;49:S59-67.

168 Sabate JM, Villarejo J, Bouhnik Y, et al. Hydrostatic balloon dilatation of Crohn's strictures. Aliment Pharmacol Ther 2003;18:409-13.

169 Suchan KL, Muldner A, Manegold BC. Endoscopic treatment of postoperative colorectal anastomotic strictures. Surg Endosc 2003;17:1110-13.

170 Boeckxstaens GE, Annese V, des Varannes SB, et al. Pneumatic dilation versus laparoscopic Heller's myotomy for idiopathic achalasia. N Engl J Med 2011:364:1807-16.

171 Ramirez FC, Dennert B, Zierer ST, et al. Esophageal self-expandable metallic stents -indications, practice, techniques, and complications: results of a national survey. Gastrointest Endosc 1997:45:360-4.

172 Johnson E, Enden T, Noreng HJ, et al. Survival and complications after insertion of self-expandable metal stents for malignant oesophageal stenosis. Scand $J$ Gastroenterol 2006;41:252-6.

173 Wang MQ, Sze DY, Wang ZP, et al. Delayed complications after esophageal stent placement for treatment of malignant esophageal obstructions and esophagorespiratory fistulas. J Vasc Interv Radiol 2001;12:465-74.

174 Neale JC, Goulden JW, Allan SG, et al. Esophageal stents in malignant dysphagia: a two-edged sword? J Palliat Care 2004;20:28-31.

175 Conio M, Repici A, Battaglia G, et al. A randomized prospective comparison of self-expandable plastic stents and partially covered self-expandable metal stents in the palliation of malignant esophageal dysphagia. Am J Gastroenterol 2007:102:2667-77.

176 May A, Hahn EG, Ell C. Self-expanding metal stents for palliation of malignant obstruction in the upper gastrointestinal tract. Comparative assessment of three stent types implemented in 96 implantations. J Clin Gastroenterol 1996;22:261-6.

177 Sabharwal T, Hamady MS, Chui S, et al. A randomised prospective comparison of the Flamingo Wallstent and Ultraflex stent for palliation of dysphagia associated with lower third oesophageal carcinoma. Gut 2003;52:922-6.

178 Saranovic D, Djuric-Stefanovic A, Ivanovic A, et al. Fluoroscopically guided insertion of self-expandable metal esophageal stents for palliative treatment of patients with malignant stenosis of esophagus and cardia: comparison of uncovered and covered stent types. Dis Esophagus 2005;18:230-8.

179 Siersema PD, Hop WC, van Blankenstein M, et al. A comparison of 3 types of covered metal stents for the palliation of patients with dysphagia caused by esophagogastric carcinoma: a prospective, randomized study. Gastrointest Endosc 2001:54:145-53.

180 Vakil N, Morris Al, Marcon N, et al. A prospective, randomized, controlled trial of covered expandable metal stents in the palliation of malignant esophageal obstruction at the gastroesophageal junction. Am J Gastroenterol 2001;96:1791-6.

181 Dormann A, Meisner S, Verin N, et al. Self-expanding metal stents for gastroduodenal malignancies: systematic review of their clinical effectiveness. Endoscopy 2004;36:543-50.

182 Telford JJ, Carr-Locke DL, Baron TH, et al. Palliation of patients with malignant gastric outlet obstruction with the enteral Wallstent: outcomes from a multicenter study. Gastrointest Endosc 2004;60:916-20.

183 Khot UP, Lang AW, Murali K, et al. Systematic review of the efficacy and safety of colorectal stents. Br J Surg 2002;89:1096-102.

184 Dionigi G, Villa F, Rovera F, et al. Colonic stenting for malignant disease: review of literature. Surg Oncol 2007;16(Suppl 1):S153-5.
185 Sebastian S, Johnston S, Geoghegan T, et al. Pooled analysis of the efficacy and safety of self-expanding metal stenting in malignant colorectal obstruction. $\mathrm{Am} J$ Gastroenterol 2004;99:2051-7.

186 Athreya S, Moss J, Urquhart G, et al. Colorectal stenting for colonic obstruction: the indications, complications, effectiveness and outcome -5 year review. Eur J Radiol 2006;60:91-4.

187 Repici A, Fregonese D, Costamagna G, et al. Ultraflex precision colonic stent placement for palliation of malignant colonic obstruction: a prospective multicenter study. Gastrointest Endosc 2007;66:920-7.

188 Meisner S, González-Huix F, Vandervoort JG, et al. Self-expandable metal stents for relieving malignant colorectal obstruction: short-term safety and efficacy within 30 days of stent procedure in 447 patients. Gastrointest Endosc 2011;74:876-84.

189 van Hooft JE, Bemelman WA, Oldenburg B, et al. Colonic stenting versus emergency surgery for acute left-sided malignant colonic obstruction: a multicentre randomised trial. Lancet Oncol 2011;12:344-52.

190 Lau G, Lai SH. Fatal retroperitoneal haemorrhage: an unusual complication of percutaneous endoscopic gastrostomy. Forensic Sci Int 2001;116:69-75.

191 Schurink CA, Tuynman H, Scholten P, et al. Percutaneous endoscopic gastrostomy: complications and suggestions to avoid them. Eur I Gastroenterol Hepatol 2001;13:819-23.

192 Ubogu EE, Zaidat 00. Rectus sheath hematoma complicating percutaneous endoscopic gastrostomy. Surg Laparosc Endosc Percutan Tech 2002;12:430-2.

193 Ruthmann O, Seitz A, Richter S, et al. [Percutaneous endoscopic gastrostomy. Complications with and without anticoagulation]. Chirurg 2010;81:247-54.

194 Richter JA, Patrie JT, Richter RP, et al. Bleeding after percutaneous endoscopic gastrostomy is linked to serotonin reuptake inhibitors, not aspirin or clopidogrel. Gastrointest Endosc 2011;74:22-34.e1.

195 Gerson LB, Tokar J, Chiorean M, et al. Complications associated with double balloon enteroscopy at nine US centers. Clin Gastroenterol Hepatol 2009; 7:1177-82, 1182.e1-3.

196 Buscaglia JM, Dunbar KB, Okolo PI III, et al. The spiral enteroscopy training initiative: results of a prospective study evaluating the Discovery SB overtube device during small bowel enteroscopy (with video). Endoscopy 2009;41:194-9.

197 Möschler O, May A, Müller MK, et al. Complications in and performance of double-balloon enteroscopy (DBE): results from a large prospective DBE database in Germany. Endoscopy 2011;43:484-9.

198 Vanbiervliet G, Giudicelli-Bornard S, Piche T, et al. Predictive factors of bleeding related to post-banding ulcer following endoscopic variceal ligation in cirrhotic patients: a case-control study. Aliment Pharmacol Ther 2010;32: 225-32.

199 Avgerinos A, Armonis A, Manolakopoulos S, et al. Endoscopic sclerotherapy versus variceal ligation in the long-term management of patients with cirrhosis after variceal bleeding. A prospective randomized study. J Hepatol 1997;26:1034-41.

200 de la Peña J, Rivero M, Sanchez E, et al. Variceal ligation compared with endoscopic sclerotherapy for variceal hemorrhage: prospective randomized trial. Gastrointest Endosc 1999;49:417-23.

201 Hou MC, Lin HC, Kuo Bl, et al. The rebleeding course and long-term outcome of esophageal variceal hemorrhage after ligation: comparison with sclerotherapy. Scand J Gastroenterol 1999;34:1071-6.

202 Petrasch F, Grothaus J, Mössner J, et al. Differences in bleeding behavior after endoscopic band ligation: a retrospective analysis. BMC Gastroenterol 2010;10:5.

203 Baigent C, Blackwell L, Collins R, et al. Aspirin in the primary and secondary prevention of vascular disease: collaborative meta-analysis of individual participant data from randomised trials. Lancet 2009;373:1849-60.

204 Hart RG, Pearce LA, Aguilar MI. Meta-analysis: antithrombotic therapy to prevent stroke in patients who have nonvalvular atrial fibrillation. Ann Intern Med 2007;146:857-67.

205 Cannegieter SC, Rosendaal FR, Briet E. Thromboembolic and bleeding complications in patients with mechanical heart valve prostheses. Circulation 1994;89:635-41. 